\title{
Impact Mechanism of Interfacial Polymer Film Formation in Aqueous Quenchants
}

\author{
Logvynenko Peter ${ }^{1,2, *}$, Moskalenko Anatoly ${ }^{3}$ \\ ${ }^{1}$ Institute of Macromolecular Chemistry of National Academy of Sciences of Ukraine, Kyiv, Ukraine \\ ${ }^{2}$ Company Barcor LTD, Kyiv, Ukraine \\ ${ }^{3}$ Institute of Engineering Thermophysics of National Academy of Sciences of Ukraine, Kyiv, Ukraine
}

Email address:

petmol@ukr.net (L. Peter), an.moskalenko@gmail.com (M. Anatoly)

${ }^{*}$ Corresponding author

\section{To cite this article:}

Logvynenko Peter, Moskalenko Anatoly Impact Mechanism of Interfacial Polymer Film Formation in Aqueous Quenchants. International Journal of Fluid Mechanics \& Thermal Sciences. Vol. 6, No. 4, 2020, pp. 108-123. doi: 10.11648/j.ijfmts.20200604.12

Received: October 8, 2020; Accepted: November 9, 2020; Published: November 23, 2020

\begin{abstract}
The results of studies of the cooling ability, rheological and surface-active properties of aqueous solutions of polyalkyleneglycol, sodium salt of carboxymethyl cellulose and polyacrylamide are presented. The choice of polymers is due to the problem of studying the mechanism of the cooling process in aqueous solutions of polymers. Comparison of the results of complex studies and video surveillance made it possible to propose a substantiated version of the mechanism of heat transfer during cooling of a metal sample in aqueous solutions of polymers. At the moment of shock boiling, a substance is formed in the wall layer, which is a nanosol (for PAG solutions) or a nanogassuspension (for Na-CMC and PAA). Under the action of a shock wave, it is directed from the heated metal surface to the interface between the polymer solution-vapor film, forming an interfacial polymer shock film. One of the stages of the shock mechanism of the formation of a polymer film is the adsorption increase in the polymer concentration on the surface of the bubbles formed during shock boiling; the next stage, the polymer shell of the bubbles, is spent on the formation of an interfacial polymer film. Heat fluxes and heat transfer coefficients are presented as a function of polymer concentration and surface temperature. The research results can be useful for assessing the effect of an interfacial polymer film on the ratio of the initial, first $\mathrm{q}_{\mathrm{cr}}{ }^{1}$ and second $\mathrm{q}_{\mathrm{cr}}{ }^{2}$ critical heat fluxes density, which determines the passage of heat transfer stages in water-polymer quenching media (WPQM).
\end{abstract}

Keywords: Aqueous Quenchants, Impact Mechanism, Interfacial Polymer Film, Chock Film Boiling

\section{Introduction}

The experience of scientific research of WPQM, the development of optimal compositions, pilot industrial tests and large-scale application in the processes of heat treatment of metals is more than 50 years old. However, at present, the study of the mechanism of the quenching process in WPQS continues, since the complex mechanism of the multistage cooling process in polymer solutions remains a subject of discussion [1-9]. Back in the $80 \mathrm{~s}$ of the last century, a model of unsteady boiling was proposed, according to which the process of cooling a sample at $\mathrm{T}>800^{\circ} \mathrm{C}$ in water goes through five stages: shock boiling in the wall layer, film boiling (FB), transition boiling (TB), nucleate boiling (NB) and convective heat transfer (CONV) [10]. According to the calculations, the time of formation of a continuous vapor layer at the initial temperature of the surface of the part $\mathrm{Ts}=840^{\circ} \mathrm{C}$ for most steels is not more than $\tau_{\mathrm{IB}}=2 \mu \mathrm{s}$, and the decrease in the temperature of the metal surface is $\Delta \mathrm{T}_{\mathrm{IB}} \approx 10^{\circ} \mathrm{C}$. Therefore, the authors of concluded that the short time of formation of the steam "blanket" and a slight decrease in the surface temperature $\Delta \mathrm{T}$ s give reason to believe that during quenching in water, the initial stage of shock boiling is replaced by the stage of film boiling. According to the authors, the simulation of the quenching cooling process taking into account 5 stages makes it possible to determine the moment, which is dangerous from the point of view of the strength of the part, when the surface cooling rate passes a critical value in the martensitic temperature range. According to [6], the use of waterpolymer quenchants makes it possible to exclude such an 
undesirable course of events, which is explained by the formation of a heat-insulating polymer film on the hot metal surface. As a result, the critical heat flux density increases, the film boiling regime is replaced by bubble boiling, after which the stage of convective heat transfer begins. It should be noted that the effect of a heat-insulating coating was first established by the authors of [11] upon cooling a nickel sample covered with a zirconium oxide film. According to the results presented in, the transition from film boiling to bubble boiling in the initial sample is observed at $215^{\circ} \mathrm{C}$, while on the sample with a $200 \mathrm{mk}$ thick zirconium oxide coating this transition occurs at $656^{\circ} \mathrm{C}$. Calculations carried out in showed that the temperature gradient between the surface and the center of the coated and uncoated specimen is $320^{\circ} \mathrm{C}$ and $460^{\circ} \mathrm{C}$, respectively, and this gradient is localized mainly in the coating. Apparently, the above results led the researchers to the idea of introducing target additives into water, for example, $\mathrm{NaCl}$ or polymers, which can form a heat-insulating coating on the metal surface that can intensify heat transfer during steel quenching [6, 7]. Since watersoluble polymers represent a whole class of high-molecularweight compounds [12], dozens of works in this promising direction were soon published. A detailed analysis of these studies shows that in most of them [5, 6], a heat-insulating film (coating) is formed on the metal surface by itself, i.e. a priori it exists, and its effect on the heat transfer process is determined by the type of polymer, its concentration and the temperature of the solution. However, there is a science adsorption of polymers [13], which studies the laws of interaction of macromolecules, i.e. polymers with a solid surface, and, as separate subsections, the interaction of macromolecules with the surface in concentrated and dilute solutions, the effect on the value of adsorption, i.e. film thickness, nature of surface and polymer. Particular attention is paid to the study of the properties of boundary layers, namely, the packing density and molecular mobility. The latter seems to be especially important, since these indicators mainly determine such thermophysical properties as thermal and thermal diffusivity [14]. Considering the above, it seems appropriate to focus on the very process of polymer film formation: factors that contribute to its appearance, location, lifetime and heat fluxes that determine its further transformation [15-17]. In the case of saline solutions, the change in the heat transfer mechanism is explained by the deposition of small salt crystals on the metal surface at the initial moments of the process. As the authors note, due to the high surface temperature, micro explosions of crystals occur, which destroy the vapor shell, thus accelerating the onset of the nucleate boiling process. The proposed scheme of heat transfer and wetting in saline solutions seems to be quite reasonable, taking into account that mineral salts of the $\mathrm{NaCl}$ type at the moment of adsorption and micro explosion do not pass the stage of thermal decomposition $\left(\mathrm{Tm}=801^{\circ} \mathrm{C}\right.$, $\mathrm{Tb}=1413^{\circ} \mathrm{C}$ ) [18]. A different situation arises when organic polymers are used as additives, the temperature of thermal decomposition of which does not exceed $450^{\circ} \mathrm{C}$ [19]. Consequently, the question arises about the mechanism of the primary act of adsorption of macromolecules on the metal surface at $\mathrm{Ts} \geq 800^{\circ} \mathrm{C}$, taking into account that the adsorption time does not exceed the duration of the shock boiling stage and is, according to various estimates, from $2 \mathrm{~ms}$ to $0.5 \mathrm{~s}$ and $1.5 \mathrm{~s}[10,19]$. Taking these circumstances into account, it is difficult to explain the formation mechanism of the nucleate boiling phase, the appearance of which is explained by the instantaneous formation of a polymer film on the metal surface $[6,15]$. It should be noted that if in the early works on the WPQM the mechanism of the formation of the polymer film was given some attention, and the main emphasis was on the mechanism of heat transfer, assuming a priori the presence of a film on the metal surface, then recently this question has practically not been raised. Considering the above, the aim of this work is to study in detail the mechanism of formation of an interfacial polymer film and its role in the process of heat transfer on the surface of a sample heated to $810^{\circ} \mathrm{C}$, taking into account that the interaction of a polymer solution with a metal begins from the moment of shock boiling [5].

\section{Materials, Devices and Experimental Technique}

\subsection{Polyalkylenglycol (PAG), $\mathrm{Mm}=35 \cdot 10^{3}(\mathrm{PAG}-35)$}

\author{
Polyacrylamide (PAA), $\mathrm{Mm}=3 \cdot 10^{6}$ \\ Sodium salt of carboxymethyl cellulose (Na-CMC), $M m=3$
} $\cdot 10^{4}$

\subsection{Installation and Technique}

A description of the laboratory thermo-acoustic system for determining the cooling properties of quenching media is given in [20].

\subsection{Investigation of the Rheological Properties of Water-polymer Quenching Media}

The dynamic viscosity of the solutions was determined by the falling ball method (Lovis 2000M viscometer, Anton Paar, Austria) and a Reotest-2 rotational viscometer (Germany) with digital indication of the results.

\section{Experimental Results}

\subsection{Rheological Properties of Polymer Solutions}

The results of studies of the dynamic viscosity of aqueous solutions of polymers are shown in Figure $1(\mathrm{a}, \mathrm{c})$, Figure 2 and Figure 3.

According to the results shown in Figure 1, Figure 2, and Figure 3 , in the area of low polymer concentrations, a close to linear dependence of the shear stress $\tau_{\mathrm{r}}$ on the shear rate Dr is observed, which makes it possible to classify such solutions as Newtonian liquids [21]. When the polymer content rises above a certain one, the so-called critical concentration (Ccr), which is determined by the 
stereochemistry of macromolecules and Mm, the Newtonian nature of the solution flow is noticeably violated (Figure 2, b and Figure 3, b), which can be explained by the formation of a network of entanglements and/or structural units in solutions [22].

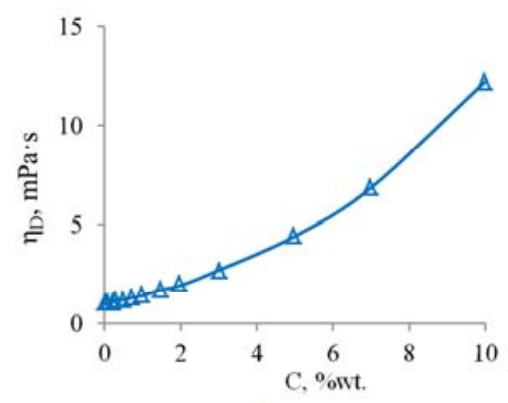

(a)

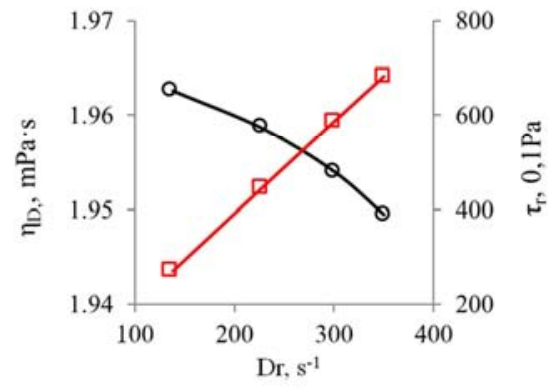

(b)

Figure 1. a) Dependence of dynamic viscosity $\eta_{D}$ of PAG-35 solutions on concentration at $T=20^{\circ} \mathrm{C}$; b) Dependence of dynamic viscosity $\eta_{D}$ and shear stress $\tau_{r}$ of PAG-35 solutions on shear rate $\mathrm{Dr}$ at $T=20^{\circ} \mathrm{C}, C_{P A G}=2 \% \mathrm{wt}$.

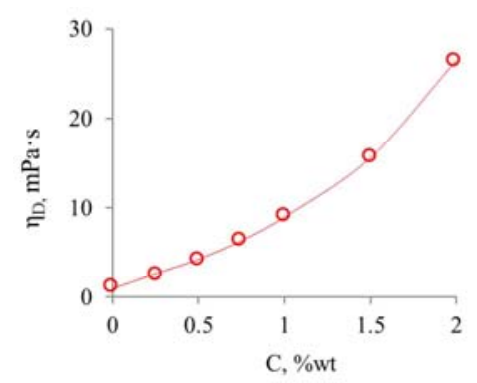

(a)

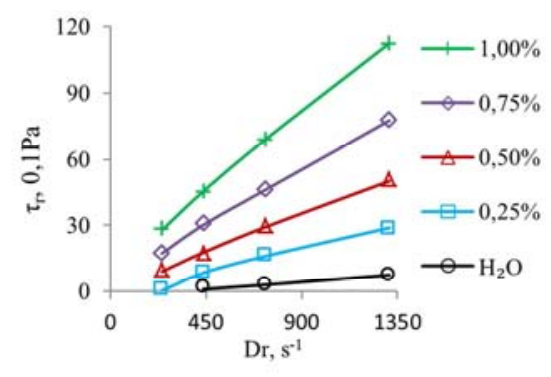

(b)

Figure 2. a) Dependence of the dynamic viscosity $\eta_{D}$ of $\mathrm{Na}$-CMC solutions on concentration at $T=20^{\circ} \mathrm{C}$, Dr $=1312 \mathrm{~s}^{-1}$; b) Dependence of the shear stress $\tau_{r}$ on the shear rate Dr and the concentration of $\mathrm{Na}-\mathrm{CMC}, \%$ wt. at $\mathrm{T}=20^{\circ} \mathrm{C}$.

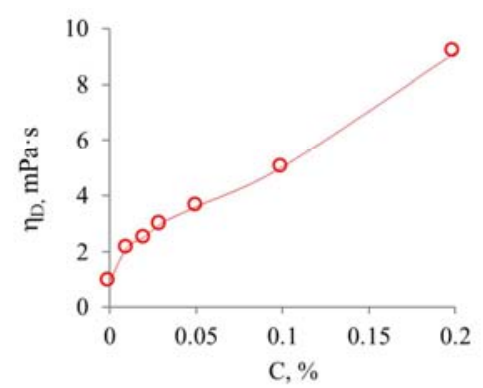

(a)

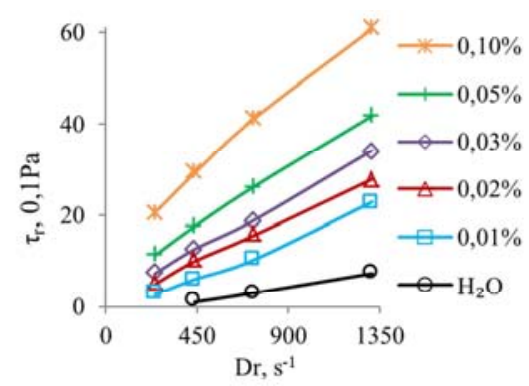

(b)

Figure 3. a) Dependence of the dynamic viscosity $\eta_{D}$ of PAA solutions on concentration at $T=20^{\circ} \mathrm{C}$, Dr $=1312 \mathrm{~s}^{-1}$; b) Dependence of the shear stress $\tau_{r}$ on the shear rate Dr and the concentration of $P A A, \%$ wt. at $T=20^{\circ} \mathrm{C}$.

\subsection{Surface Tension of Polymer Solutions}

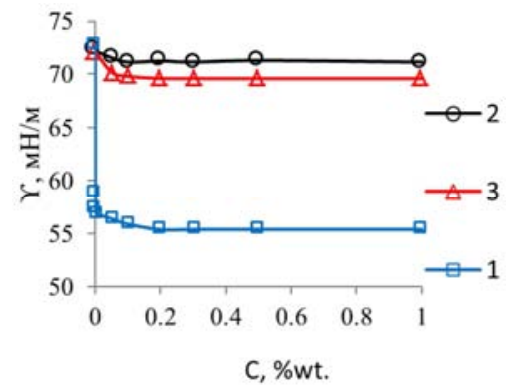

Figure 4. Dependence of surface tension $\gamma$ of aqueous solutions of PAG-35 (1), Na-CMC (2) and PAA (3) on the concentration of polymers at $T=20^{\circ} \mathrm{C}$.
According to [23], one of the quality criteria for quenching media is wettability; surface tension, which significantly affects the processes of nucleation, growth and detachment of bubbles during the period of nucleate boiling. To assess the wettability of polymer solutions, the surface tension $(\gamma)$ was studied using the modified plate (platinum) Wilhelmy method [24].

As can be seen from the results shown in Figure 4, of the three polymers, only PAG-35 can be attributed to the surfactant class, since at a sufficiently low concentration ( $\sim 0.1 \%$ wt.), the $\gamma$ values decrease by almost $20 \mathrm{mN} / \mathrm{m}$. The polyelectrolyte $\mathrm{Na}-\mathrm{CMC}$ and the amine-containing PAA reduce the $\gamma$ values by only $1.0-2.0 \mathrm{mN} / \mathrm{m}$, which does not allow them to be classified as surfactants. 


\subsection{Effect of Polymer Concentration on Cooling Curves $\left(T,{ }^{\circ} \mathrm{C}\right)$ and Cooling Rate of the Thermal Probe (dT, $\left.{ }^{\circ} \mathrm{C} / \mathrm{s}\right)$}

\subsubsection{Cooling in Aqueous Solutions PAG-35}

Figure 5 shows the curves of cooling and the cooling rate in PAG-35 solutions in a wide range of polymer concentrations in distilled water, in Table 1 indicators of the cooling process of the thermal probe in PAG-35 solutions.

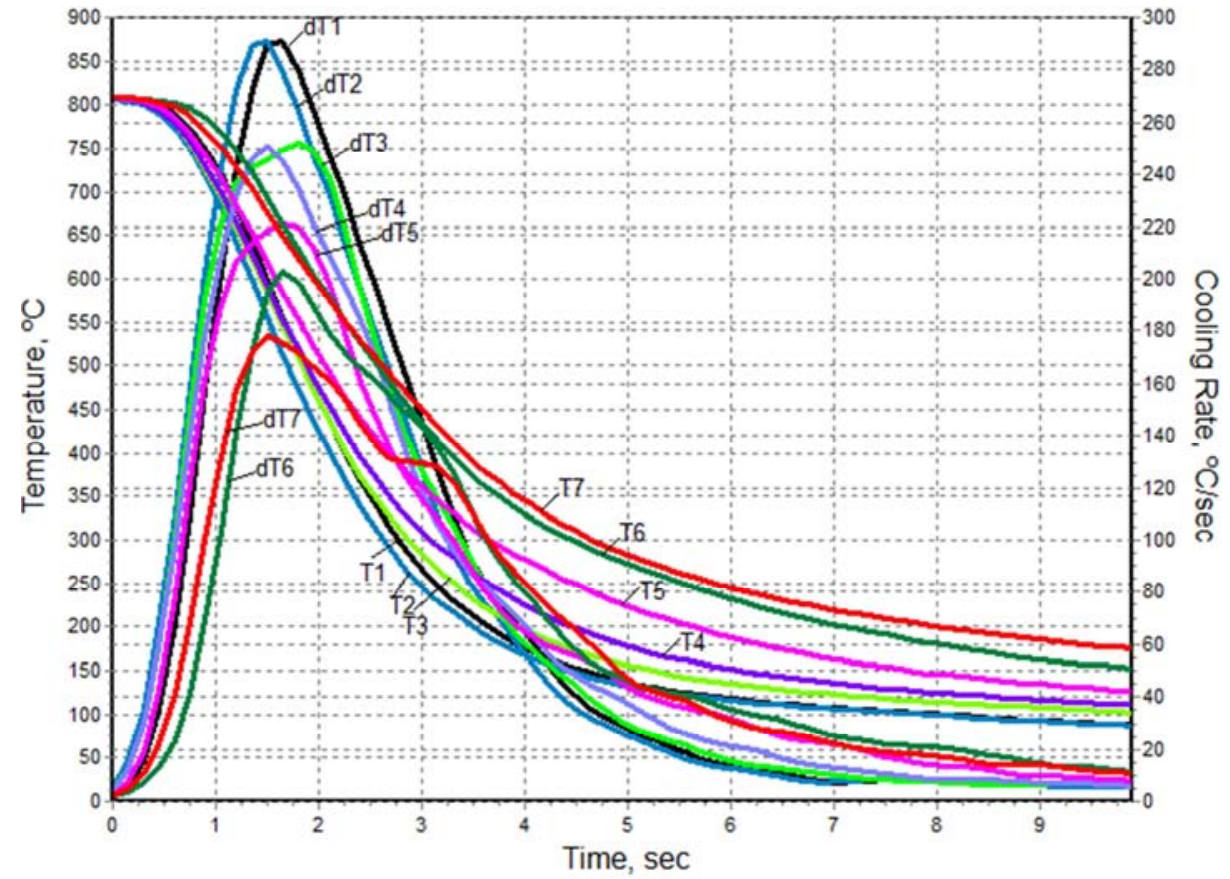

(a)

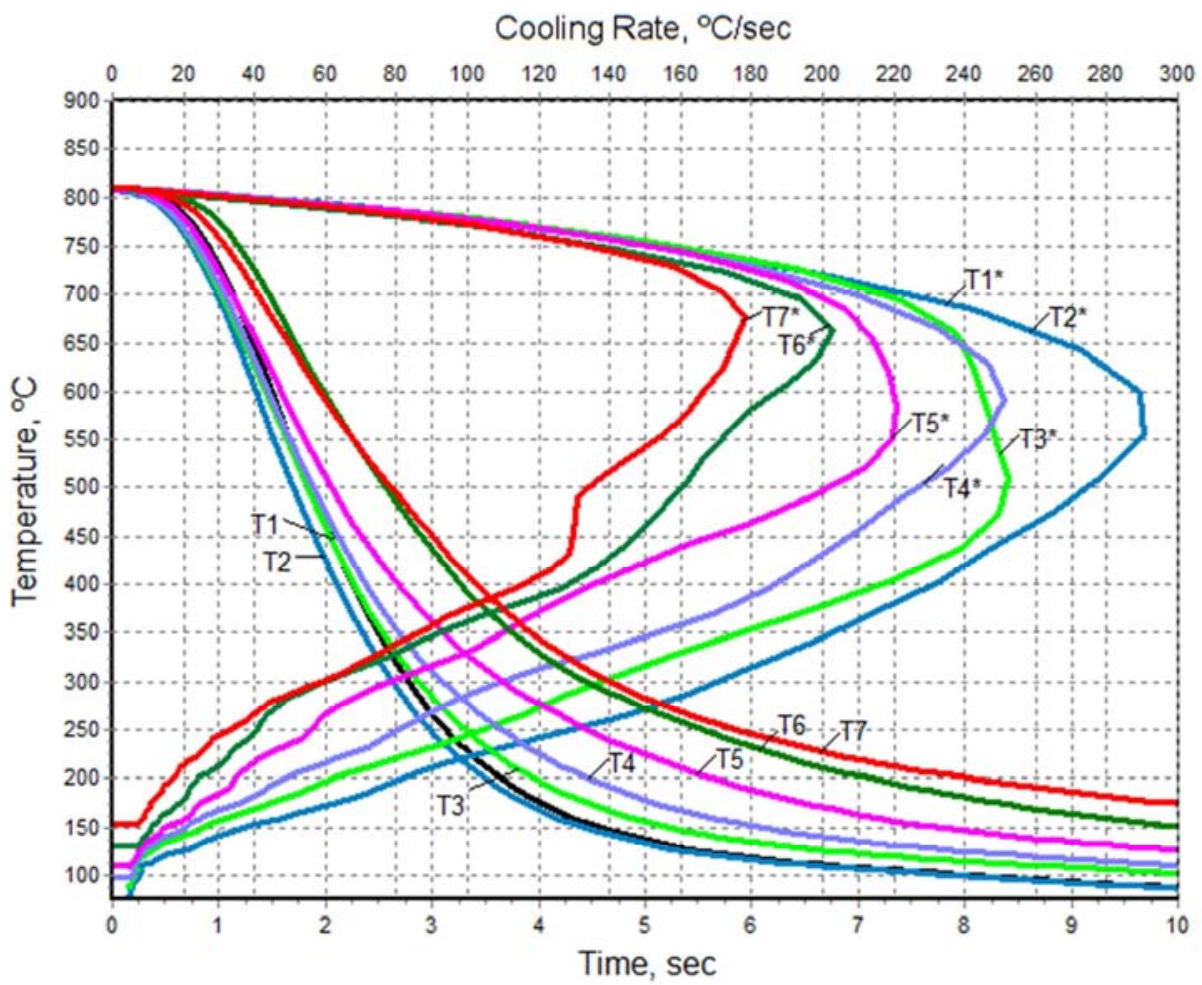

(b)

Figure 5. Curves of temperature and cooling rate of thermal probe in PAG35, concentration, \%wt.: 1-0,0;2-1,0;3-2,0;4-3,0;5-5,0;6-7,0; 7 - 10,0: a) $T$ and $d T$; b) $T$ and $T^{*}$. 
Table 1. Cooling parameters obtained by IS09950 at $20^{\circ} \mathrm{C}$ bath temperature and with no agitation.

\begin{tabular}{|c|c|c|c|c|c|c|c|c|c|}
\hline \multirow{2}{*}{ No. } & \multirow{2}{*}{ Indicator (unit) } & \multirow{2}{*}{$\begin{array}{l}\text { Cond. } \\
\text { Design. }\end{array}$} & \multicolumn{7}{|c|}{ Concentration of PAG-35, \%wt. } \\
\hline & & & $\mathbf{0 , 0}$ & 1,0 & 2,0 & $3, \mathbf{0}$ & 5,0 & 7,0 & 10,0 \\
\hline 1 & Probe Cooling Time from $850^{\circ} \mathrm{C}$ to $600^{\circ} \mathrm{C}, \mathrm{s}$ & $\tau_{600}$ & 1,4 & 1,5 & 1,4 & 1,5 & 1,6 & 2,0 & 1,9 \\
\hline 2 & Probe Cooling Time from $850^{\circ} \mathrm{C}$ to $400^{\circ} \mathrm{C}, \mathrm{s}$ & $\tau_{400}$ & 2,2 & 2,3 & 2,3 & 2,4 & 2,7 & 3,3 & 3,4 \\
\hline 3 & Probe Cooling Time from $850^{\circ} \mathrm{C}$ to $200^{\circ} \mathrm{C}, \mathrm{s}$ & $\tau_{200}$ & 3,7 & 3,9 & 4,0 & 4,5 & 5,6 & 7,1 & 8,0 \\
\hline 4 & Maximum cooling rate, ${ }^{\circ} \mathrm{C} / \mathrm{s}$ & $\mathrm{V}_{\mathrm{t}}^{\max }$ & 292 & 294,5 & 252,1 & 251,0 & 220,8 & 202,6 & 178,0 \\
\hline 5 & Temperature TP at max. cooling rate, ${ }^{\circ} \mathrm{C}$ & $\mathrm{T}_{\mathrm{TP}} \operatorname{Vtmax}$ & 539 & 540 & 510 & 591 & 586 & 663 & 676 \\
\hline 6 & Cooling rate, at temperature $\mathrm{TP}=300^{\circ} \mathrm{C},{ }^{\circ} \mathrm{C} / \mathrm{c}$ & $\mathrm{V}_{\mathrm{t}}^{\mathrm{TTP} 300}$ & 142,8 & 133,5 & 127,0 & 106,3 & 73,8 & 57,6 & 54,1 \\
\hline
\end{tabular}

Aqueous solutions of PAG have the property that the polymer loses its solubility during the so-called inversion temperature in the range of $65-80^{\circ} \mathrm{C}[5,7,15]$, and when cooled below, PAG again dissolves completely in water. According to [15], PAG solutions withstand such multiple cycles, which is confirmed by the long (up to 10 years) period of their operation under industrial conditions. Therefore, at present there are publications in which the subject of research is the detailed mechanism of the heat transfer process [25-27]. In this case, it is necessary to use a PAG with a known Mm, since it determines the optimal viscosity range in which the required temperature regime for metal cooling is realized.

According to the results of preliminary experiments, PAG additives with $\mathrm{Mm} \geq 35 \cdot 10^{3}$ at a concentration of $\mathrm{C} \geq 1.0 \% \mathrm{wt}$. have a noticeable effect on the cooling process. (Figure 5 a, b). In the concentration range from $2.0 \% \mathrm{wt}$. up to $10.0 \% \mathrm{wt}$. there is a significant decrease in the $\mathrm{V}_{\mathrm{t}}^{\max }$ and $\mathrm{V}_{\mathrm{t}}^{\mathrm{T}}=300$ indicators by $40 \%$ and $60 \%$, respectively, and for the $\mathrm{T}_{\mathrm{TP}}{ }^{\mathrm{Vtmax}}$ indicator - an increase by $65 \%$ (Table 1). A significant decrease $(\sim 3$ times $)$ in the cooling rate $\left(V_{t}^{\text {TTP300 }}\right)$ in the lower martensitic temperature range is a positive result, since this reduces the risk of residual stresses and cracks [28]. The transition of the $\mathrm{T}_{\mathrm{TP}}{ }^{\mathrm{Vtmax}}$ index to the high-temperature area
(Figure 5, b, Table 1) indicates that the transition of film boiling to bubble boiling occurs in the area of higher temperatures beyond the boundary of the martensitic interval [10]. Considering that the dynamic viscosity of water and $1 \%$ PAG-35 solution differ by about $9 \%$ (Figure 1), and the surface tension of the $(\gamma)$ PAG-35 solution is $20 \%$ lower than the $\gamma$ values for water, therefore, PAG additives affect the nucleate boiling phase [23]. This is confirmed by the appearance of an inflection on the curves of the cooling rate dT6, T6* and a clear shoulder on the curves dT7, T7* when the thermal probe is cooled in PAG-35 solutions with a concentration of $7 \% \mathrm{wt}$. and $10 \% \mathrm{wt}$., respectively (Figure 5).

\subsubsection{Cooling in Na-CMC Solutions}

$\mathrm{Na}-\mathrm{CMC}$ is a salt of a weak carboxylic acid and therefore behaves like a polyelectrolyte in aqueous solutions [17] and is easily combined with water-soluble products - starch, glycols, glycerol, corrosion inhibitors, and biocides. Due to this, solutions of $\mathrm{Na}-\mathrm{CMC}$ are used as a base in the development of water-polymer quenching agents, which are used in the quenching of high-alloy and heat-resistant steels [29, 30]. Figure 6 shows the curves of cooling and the cooling rate, there are indicators of the cooling process of the thermal probe in Na-CMC solutions in Table 2.

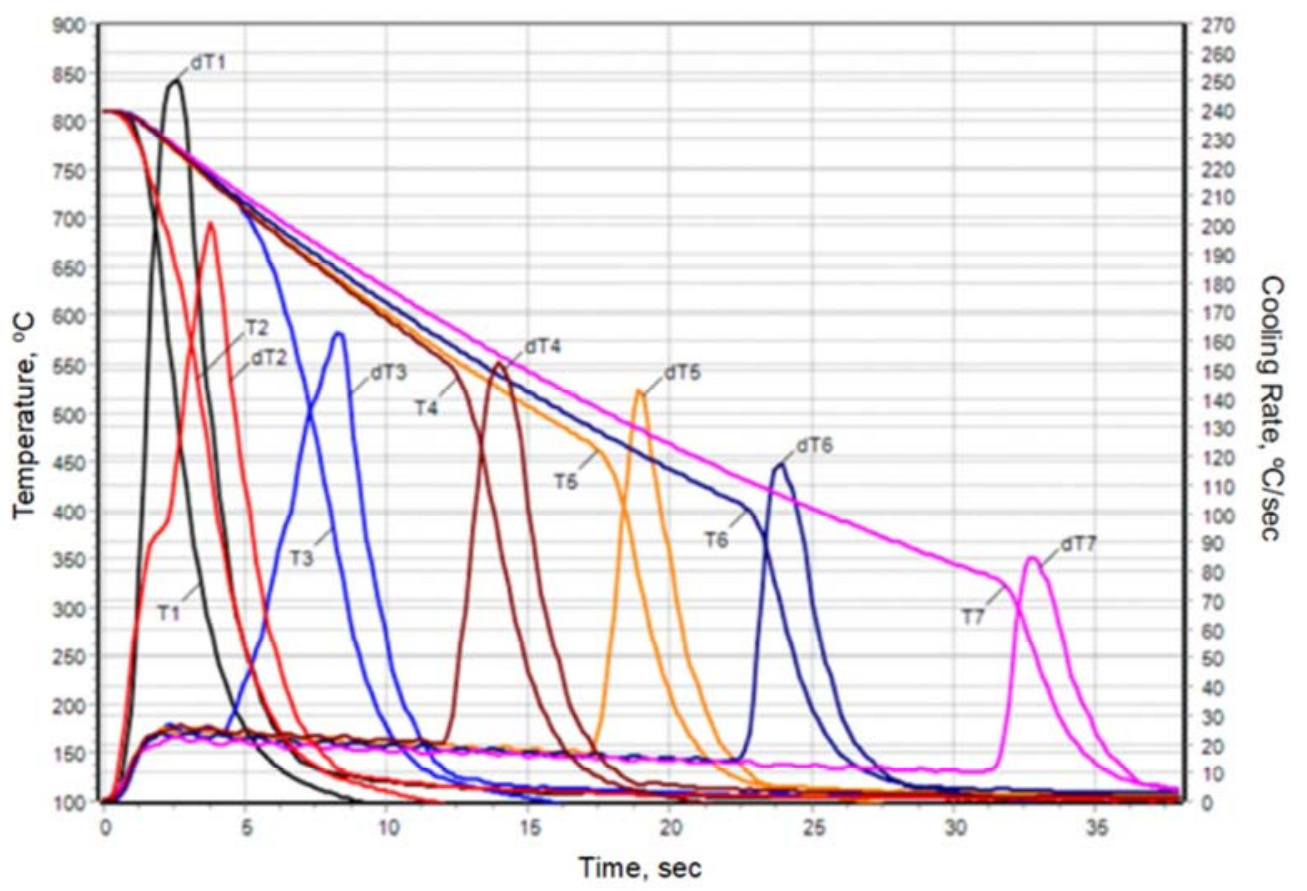

(a) 


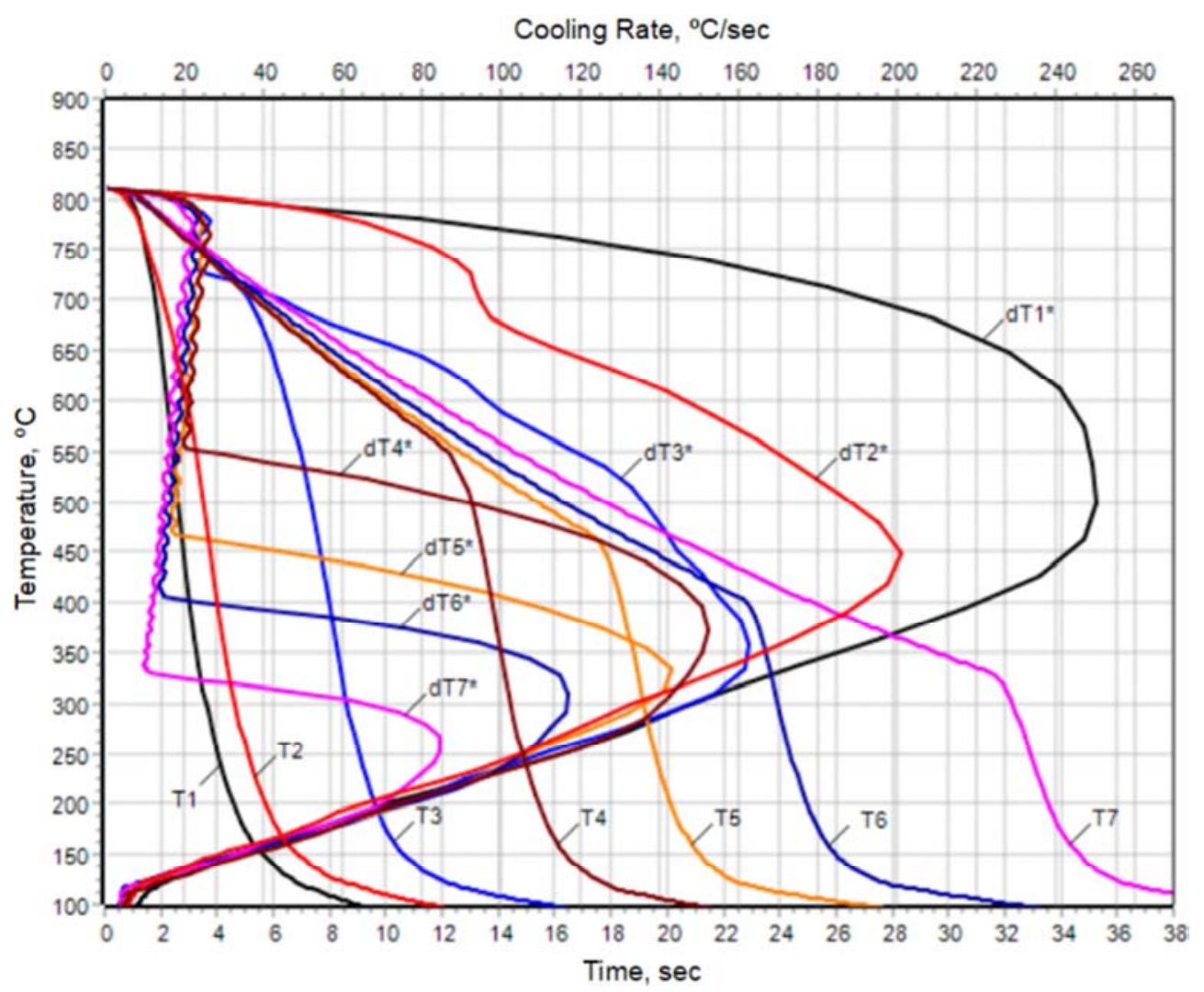

(b)

Figure 6. Curves of temperature and cooling rate of thermal probe in Na-CMC, concentration, \%wt.: $1-0,0 ; 2-0,25 ; 3-0,50 ; 4-0,75 ; 5-1,0 ; 6-1,5 ; 7-$ 2,0: a) $T$ and $d T$; b) $T$ and $T^{*}$.

Table 2. Cooling parameters obtained by IS09950 at $20^{\circ} \mathrm{C}$ bath temperature and with no agitation.

\begin{tabular}{|c|c|c|c|c|c|c|c|c|c|}
\hline \multirow{2}{*}{ No. } & \multirow{2}{*}{ Indicator (unit) } & \multirow{2}{*}{$\begin{array}{l}\text { Cond. } \\
\text { Design. }\end{array}$} & \multicolumn{7}{|c|}{ Concentration of $\mathrm{Na}-\mathrm{CMC}, \% \mathrm{wt}$. } \\
\hline & & & $\mathbf{0 , 0}$ & $\mathbf{0 , 2 5}$ & $\mathbf{0 , 5 0}$ & $\mathbf{0 , 7 5}$ & 1,0 & 1,5 & 2,0 \\
\hline 1 & Probe Cooling Time from $850^{\circ} \mathrm{C}$ to $600^{\circ} \mathrm{C}, \mathrm{s}$ & $\tau_{600}$ & 2,2 & 2,8 & 6,5 & 10,0 & 10,1 & 10,7 & 11,7 \\
\hline 2 & Probe Cooling Time from $850^{\circ} \mathrm{C}$ to $400^{\circ} \mathrm{C}, \mathrm{s}$ & $\tau_{400}$ & 3,0 & 3,9 & 8,0 & 14,2 & 18,4 & 22,9 & 25,2 \\
\hline 3 & Probe Cooling Time from $850^{\circ} \mathrm{C}$ to $200^{\circ} \mathrm{C}, \mathrm{s}$ & $\tau_{200}$ & 4,6 & 5,6 & 9,6 & 15,8 & 20,2 & 25,1 & 33,6 \\
\hline 4 & Maximum cooling rate, ${ }^{\circ} \mathrm{C} / \mathrm{s}$ & $\mathrm{V}_{\mathrm{t}}^{\max }$ & 250,6 & 201,2 & 162,7 & 157,2 & 138,4 & 114,1 & 82,5 \\
\hline 5 & Temperature TP at max. cooling rate, ${ }^{\circ} \mathrm{C}$ & $\mathrm{T}_{\mathrm{TP}}^{\mathrm{Vtmax}}$ & 499 & 458 & 357 & 388 & 339 & 303 & 258 \\
\hline 6 & Cooling rate, at temperature $\mathrm{TP}=300^{\circ} \mathrm{C},{ }^{\circ} \mathrm{C} / \mathrm{s}$ & $\mathrm{V}_{\mathrm{t}}^{\mathrm{TTP} 300}$ & 144,0 & 124,6 & 141,0 & 140,1 & 130,8 & 112,7 & 69,2 \\
\hline
\end{tabular}

A fairly low concentration of $0.25 \%$ wt. polymer in CMC significantly affects the course of the cooling curves and the cooling rate (Figure $6(\mathrm{a}, \mathrm{b})$, Table 2). On the cooling curve $\mathrm{dT} 2$, a noticeable "shoulder" is observed at $\tau=1.6 \mathrm{~s}$, and the maximum of the dT2 curve is located near $\tau=3.3 \mathrm{~s}$, while the maximum of the dT 1 curve of water is observed at $\tau=2.2 \mathrm{~s}$. It is interesting that such a separation of the position of the maximum of the cooling rate curve was established when small concentrations of carbon nanotubes (CNT) were added to water [31]. The possibility of the formation of nanoparticles in aqueous solutions of Na-CMC was established in [32], while their radius decreases with increasing temperature and solution concentration. The effect of small additives $(0.25 \% \mathrm{wt}$.) is accompanied by a sharp decrease of $\mathrm{V}_{\mathrm{t}}{ }^{\max }$ values compared to water: $\Delta \mathrm{V}_{\mathrm{t}}^{\mathrm{max}}=49.4^{\circ} \mathrm{C} / \mathrm{s}$ (Table 2), i.e. by almost $20 \%$. With an increase in the concentration of Na-CMC to $0.5 \%$ weight an inflection is observed on the curves $\mathrm{dT} 3$ and $\mathrm{T} 3 *$, while the value of $\Delta \mathrm{V}_{\mathrm{t}}^{\max }=87.5^{\circ} \mathrm{C} / \mathrm{s}$, and an increase of the polymer content to $0.75 \%$ wt. is accompanied by a slowdown in the decrease in $\Delta \mathrm{V}_{\mathrm{t}}^{\max }$ to $93.0^{\circ} \mathrm{C} / \mathrm{s}$. Analysis of the dynamics of the decrease of $\mathrm{V}_{\mathrm{t}}^{\max }$ values in the concentration range from $0.0 \%$ to $0.75 \%$ inclusive shows that it has a character close to exponential. Subsequent decrease in $\mathrm{Vt}^{\max }$ values with increasing concentration in relation to $\mathrm{V}_{\mathrm{t}}^{\max }$ at $\mathrm{C}=0.75 \% \mathrm{wt}$. obeys a linear law, which gives grounds to assume the existence of two different heat transfer processes in Na-CMC solutions. The first one is in the area of low concentrations of $0.0 \%-0.50 \%$ wt., in which the cooling proceeds sequentially through the stages: shock boiling, boiling of the shock film [33], nucleate boiling and convection, while the first stage ends with the formation of a polymer film.

With an increase in the concentration of $\mathrm{Na}-\mathrm{CMC}$ to $0.75 \%$ wt. (Figure $6, \mathrm{~b}$, curve $\mathrm{T} 4 *$ ) the second cooling mechanism is realized, as evidenced by a sharp, almost 3fold increase in the duration of film boiling. With a slight change of the parameters $\mathrm{V}_{\mathrm{t}}^{\max }, \mathrm{T}_{\mathrm{TP}}^{\mathrm{Vtmax}}$ and $\mathrm{V}_{\mathrm{t}}^{\mathrm{TTP300}}$, an 
increase in the cooling kinetics indices $\tau_{600}, \tau_{400}$ and $\tau_{200}$ by $1.5,1.8$, and 1.6 times, respectively, is observed (Table 2). With a further increase in the content of $\mathrm{Na}-\mathrm{CMC}$ in the solution, the cooling mode is retained, as evidenced by the congruence of the T4*-T7* curves (Figure 6, b). A significant increase in the duration of the vapor phase can be explained by the formation at the interface between $\mathrm{Na}-\mathrm{CMC}$ solution of a polymer film, the thickness and strength of which increases with the increase of concentration of $\mathrm{Na}-\mathrm{CMC}$. Such a film can form on the surface of the polymer solution almost instantly; at the end of the shock boiling stage, as a result of hydrodynamic shock. The strength of such a film will be determined not only by the concentration of the polymer, but also by its physical and mechanical properties. It can be assumed that the first variant of the heat transfer process is realized with the participation of individual isolated $\mathrm{Na}-\mathrm{CMC}$ nanoparticles, and with an increase in the polymer concentration, associates of $\mathrm{Na}-\mathrm{CMC}$ nanoparticles participate in the formation of an impact of polymer film. The analysis of the results from Figure 6, (a) shows that the threshold concentration at which a sufficiently stable polymer film is formed is about $0.4 \%$ wt.

\subsubsection{Cooling in PAA Solutions}

Polyacrylamide belongs to a series of linear water-soluble polymers that effectively reduce resistance in a turbulent flow of liquids [12]. This effect manifests itself at very low concentrations $\left(\sim 10^{-4} \%\right.$ of high molecular weight PAA $\left(\mathrm{Mm}=1 \cdot 10^{6}-7 \cdot 10^{6}\right)$. In aqueous solutions, the PAA macromolecules have the form of a nanosized statistical coil, the dimensions of which are determined by $\mathrm{Mm}$ and the temperature of the solution [12]. Figure $7(a, b)$ shows the results of the study of the cooling curves, the cooling rate, the parameters of the cooling process in PAA solutions are listed in Table 3.

Table 3. Cooling parameters obtained by IS09950 at $20^{\circ} \mathrm{C}$ bath temperature and with no agitation.

\begin{tabular}{|c|c|c|c|c|c|c|c|c|}
\hline \multirow{2}{*}{ No. } & \multirow{2}{*}{ Indicator (unit) } & \multirow{2}{*}{$\begin{array}{l}\text { Cond. } \\
\text { Design. }\end{array}$} & \multicolumn{6}{|c|}{ Concentration of PAG-35, \%wt. } \\
\hline & & & $\mathbf{0 , 0}$ & 0,0075 & 0,015 & $\mathbf{0 , 0 0 3}$ & $\mathbf{0 , 0 5}$ & $\mathbf{0 , 1 0}$ \\
\hline 1 & Probe Cooling Time from $850^{\circ} \mathrm{C}$ to $600^{\circ} \mathrm{C}, \mathrm{s}$ & $\tau_{600}$ & 2,5 & 3,5 & 7,0 & 11,1 & 12,2 & 13,3 \\
\hline 2 & Probe Cooling Time from $850^{\circ} \mathrm{C}$ to $400^{\circ} \mathrm{C}, \mathrm{s}$ & $\tau_{400}$ & 3,9 & 5,1 & 8,7 & 14,2 & 20,0 & 26,7 \\
\hline 3 & Probe Cooling Time from $850^{\circ} \mathrm{C}$ to $200^{\circ} \mathrm{C}, \mathrm{s}$ & $\tau_{200}$ & 7,1 & 9,1 & 13,0 & 18,8 & 24,9 & 34,2 \\
\hline 4 & Maximum cooling rate, ${ }^{\circ} \mathrm{C} / \mathrm{s}$ & $\mathrm{V}_{\mathrm{t}}^{\max }$ & 169,1 & 149,2 & 135,8 & 77,0 & 53,1 & 40,5 \\
\hline 5 & Temperature TP at max. cooling rate, ${ }^{\circ} \mathrm{C}$ & $\mathrm{T}_{\mathrm{TP}}^{\mathrm{Vtmax}}$ & 570 & 633 & 571 & 438 & 356 & 276 \\
\hline 6 & Cooling rate, at temperature $\mathrm{TP}=300^{\circ} \mathrm{C},{ }^{\circ} \mathrm{C} / \mathrm{s}$ & $\mathrm{V}_{\mathrm{t}}^{\mathrm{TTP} 300}$ & 69,3 & 57,3 & 52,4 & 48,5 & 46,2 & 37,6 \\
\hline
\end{tabular}

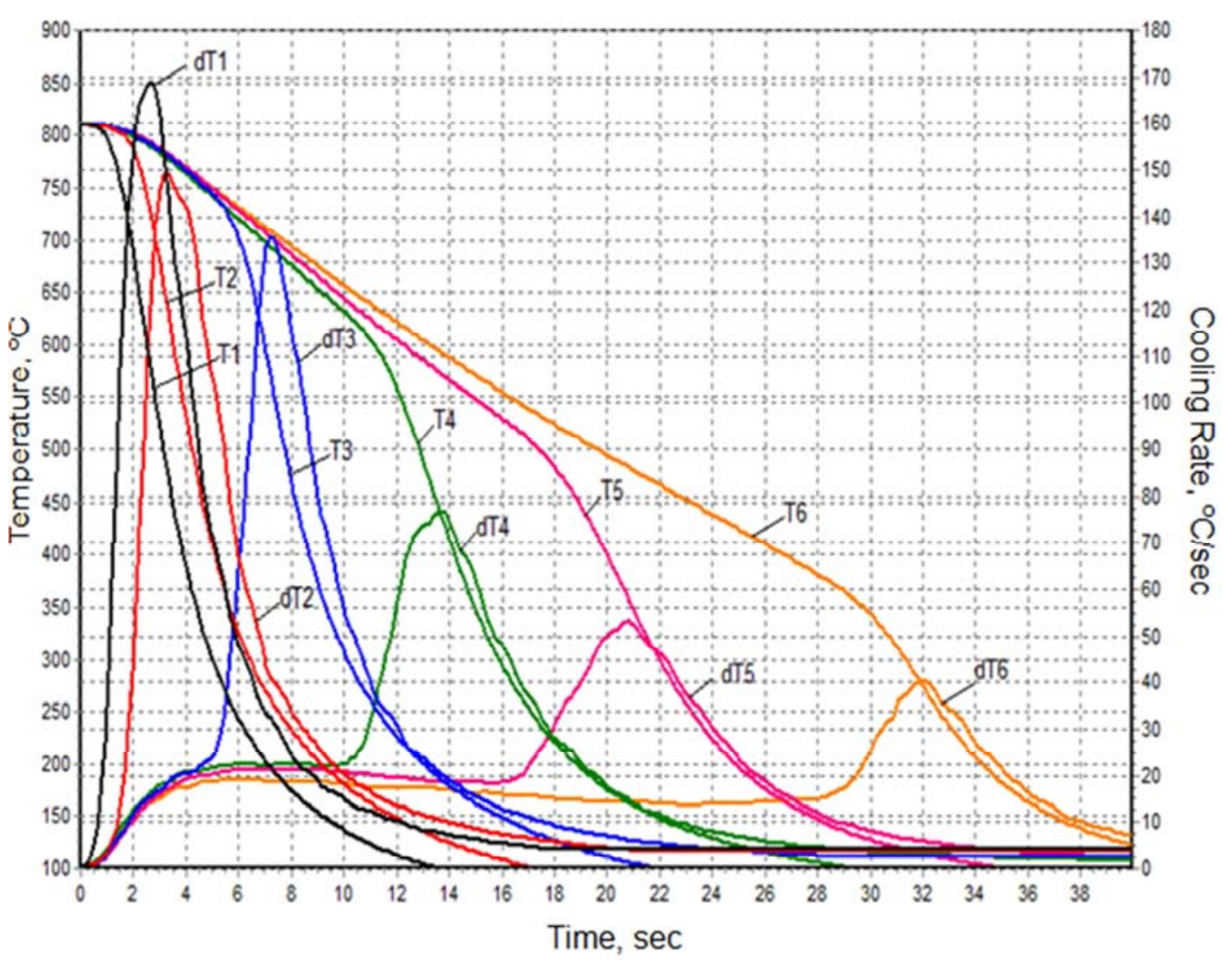




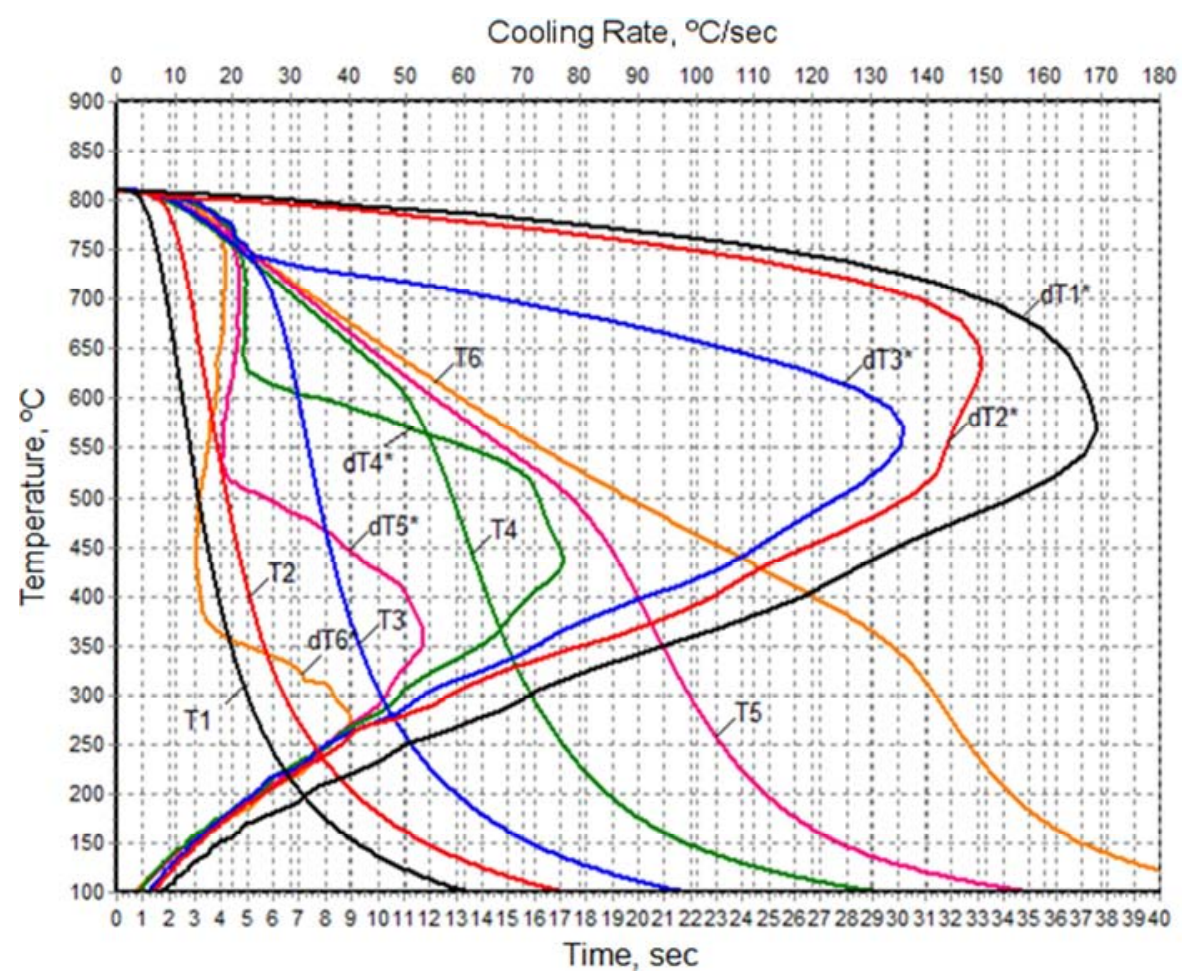

(b)

Figure 7. Curves of temperature and cooling rate of thermal probe in PAA, concentration, \%wt.: $1-0,0 ; 2-0,0075 ; 3-0,015 ; 4-0,03 ; 5-0,05 ; 6-0.10:$ a) $T$ and $d T$; b) $T$ and $T^{*}$.

A comparative analysis of the results shown in Figures 6 and 7 for aqueous solutions of $\mathrm{Na}-\mathrm{CMC}$ and PAA indicates a significant similarity of the concentration dependences of the cooling curves, the cooling rate $\mathrm{dT}$, and the cooling rate $\mathrm{T}^{*}$ on temperature. Taking this into account, it seems possible that the above description of the results of studies of $\mathrm{Na}$ CMC solutions can be attributed to PAA solutions. As in the case of Na-CMC solutions (Figure 6, b), the entire spectrum of cooling rate curves clearly divided into two families depending on the polymer concentration: $0.0 \%-0.015 \%$ wt. and $0.03 \%-0.10 \%$ wt., in which the corresponding cooling mechanism is realized: shock boiling $\rightarrow$ shock polymer film $\rightarrow$ film boiling $\rightarrow$ nucleate boiling $\rightarrow$ convection. In the formation of a shock polymer film, by analogy with the NaCMC solution, both individual nanosized PAA coils and associates participate, and the threshold concentration of Na-
CMC is about $0.015 \%$ wt.

\subsection{Video Surveillance of the Cooling Process in Polymer Solutions}

\subsubsection{PAG-35 Solutions}

In the experiments, we used an ELP-USBFHDOGH-SFV USB webcam, 30 frames per second, connected to a $\mathrm{PC}$ via an X96Max attachment, for online observation, an installation and a technique for capturing a TP image in a hardening environment, allowing to record fast processes of phase transitions at unsteady boiling. The duration of shooting the process and fixing the fragments were chosen in accordance with the results shown in Figure 5, a, Figure 6, a and Figure 7, a. For comparison, Figure 8 shows the results of video surveillance of TP when cooled in distilled water.

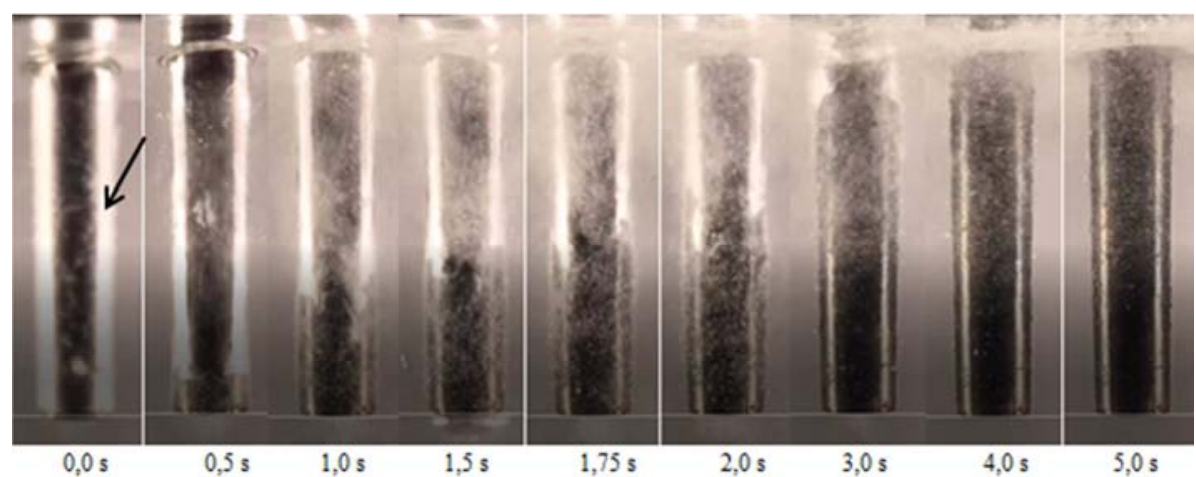

Figure 8. Formation of heat transfer stages during cooling in distilled water at $T=20^{\circ} \mathrm{C}$. 
The boiling phase of the water vapor film occurs at the moment of shock boiling (arrow), and approximately $0.5 \mathrm{sec}$. from the lower end of the TP, its destruction begins, which ends by the end of the 2 nd sec. of exposure. Then there is a repeated wetting, a transition to the NB phase, then to CONV.

Boiling of the film at the moment of shock boiling is clearly seen in Figure 9, but after $0.1 \mathrm{sec}$. cloudiness appears around the TP, which is accompanied by an explosion, rewetting and transition to the NB phase. Cloudiness is observed until the beginning of the 2 nd sec., then it transforms, and after $2 \mathrm{sec}$. begins to disappear from the lower end of the TP. After the 10th sec., the cooling moves to the convection phase.
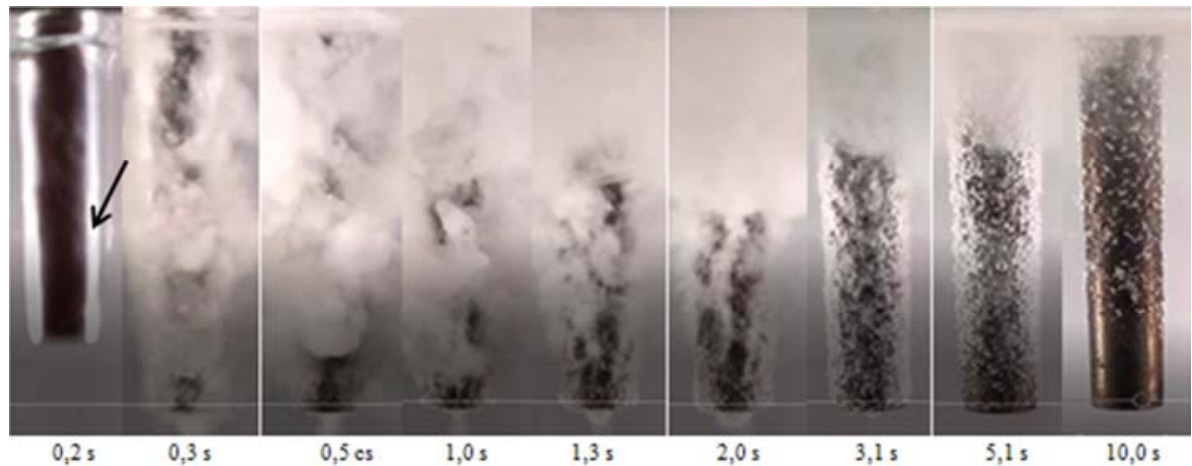

Figure 9. Formation of heat transfer stages in a $P A G-35$ solution in water, $C=1.5 \%$ wt., $T=20^{\circ} \mathrm{C}$.

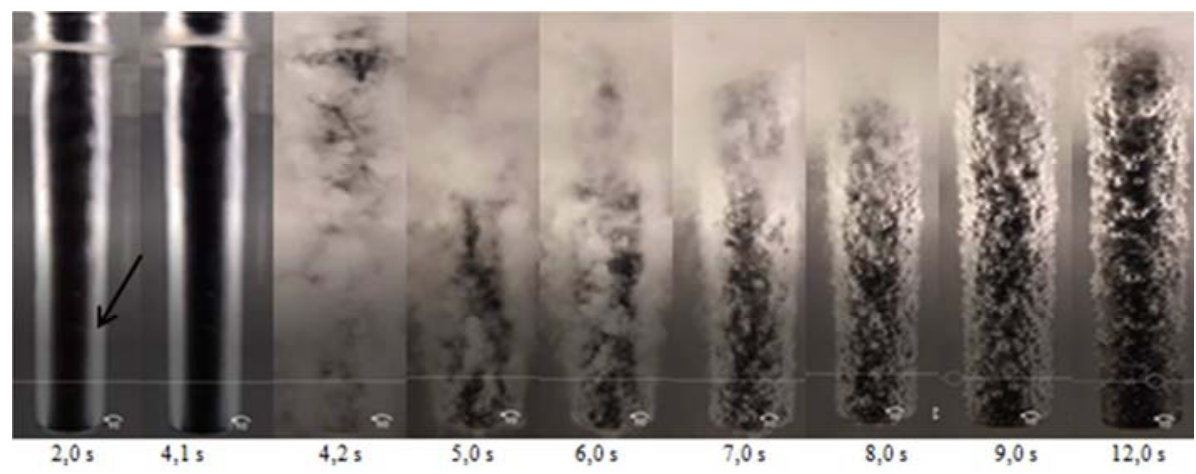

Figure 10. Formation of heat transfer stages in a $P A G-35$ solution in water, $C=3.0 \% \mathrm{wt}$., $T=20^{\circ} \mathrm{C}$.

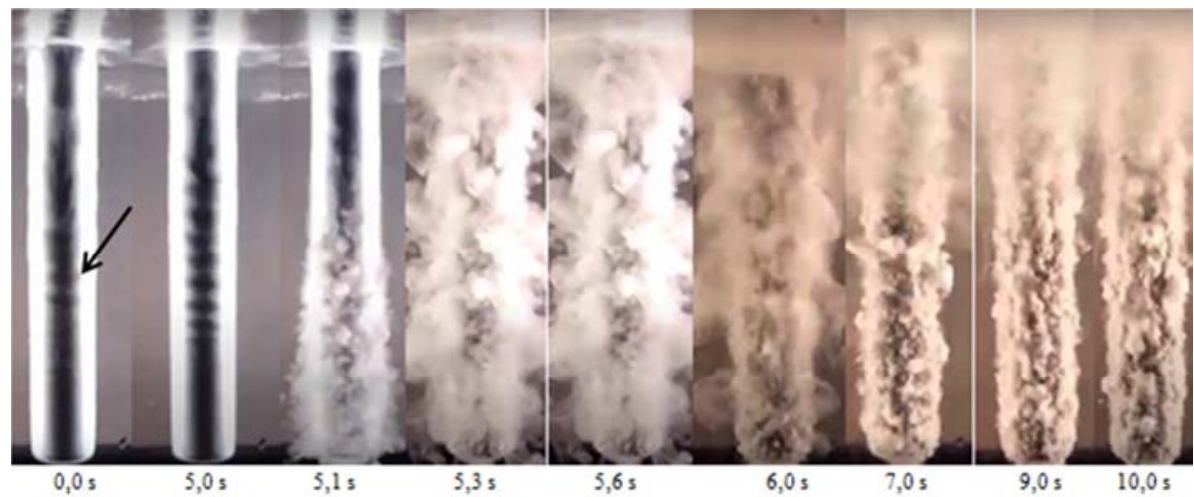

Figure 11. Formation of heat transfer stages during cooling of $T Z$ in a $P A G-35$ solution in water, $C=7.0 \%$ wt., $T=20^{\circ} \mathrm{C}$.

Boiling of the shock film continues until the 5 th second (Figure 10), it completely covers the surface of the TP. Immediately after the 4th second, cloudiness appears, accompanied by an explosion, rewetting and transition to the NB phase. After 2 seconds, the cloud compresses, changes its shape and size, and after the 12th second, the NB phase moves to the convection phase.

The boiling phase of the shock film is observed up to the 5 th second inclusively (Figure 11); it completely and evenly covers the surface of the TP. Immediately after the 5th second, cloudiness appears from the lower end of the TP, which takes 0.2 seconds, covers the entire surface, an explosion occurs, followed by rewetting and transition to the NB phase. Cloudiness is observed until the 6th second, then its shape and size change, remains on the surface of the TP in the form of a rather thick loose film, the NB phase lasts until the 10th sec. inclusively. 


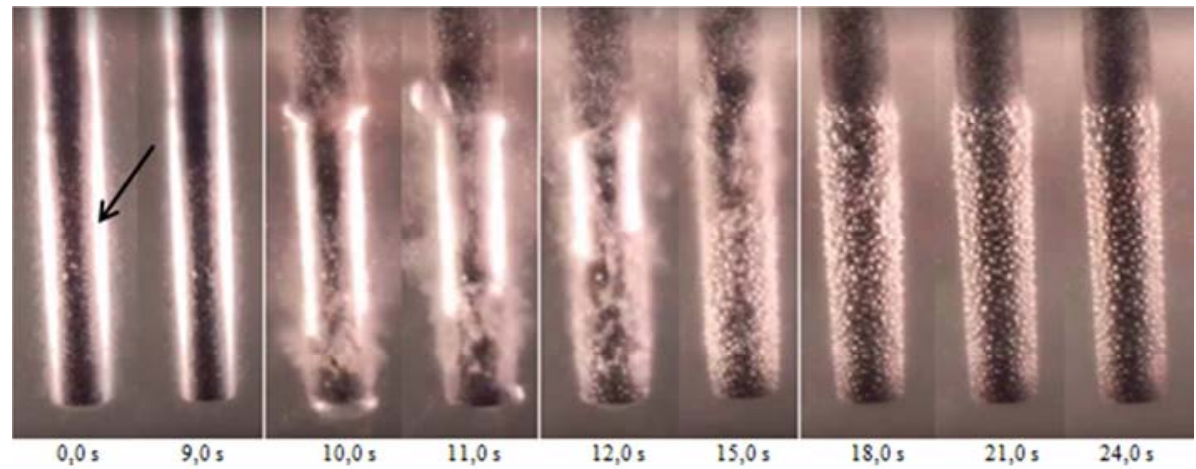

Figure 12. Formation of stages of heat transfer during cooling in a solution of $\mathrm{Na}$-CMC in water: $C=0.65 \%$ wt., $T=20^{\circ} \mathrm{C}$.

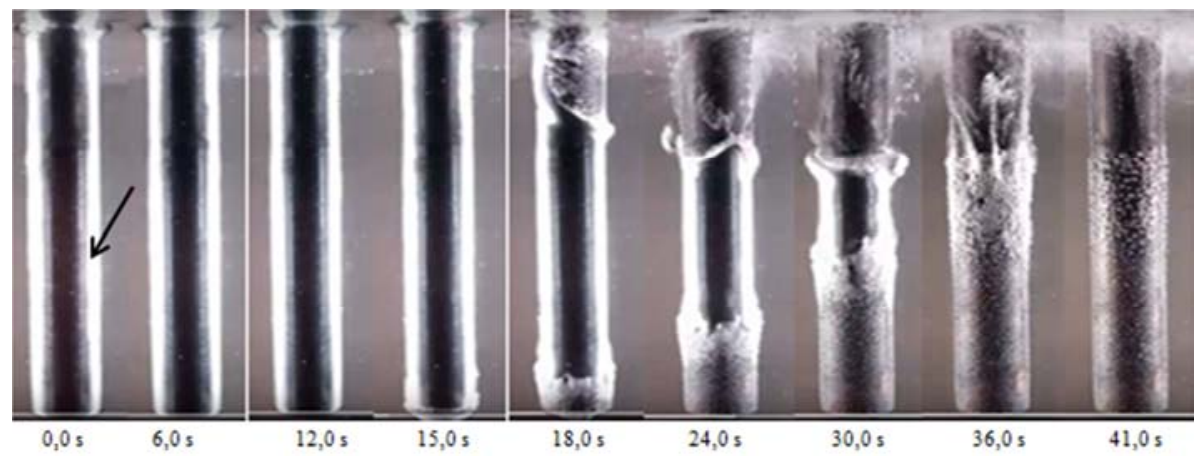

Figure 13. Formation of heat transfer stages during cooling in a PAA solution in water: $C=0.06 \%$ wt., $T=20^{\circ} \mathrm{C}$.

\subsubsection{Video Surveillance of Na-CMC Solutions}

The boiling phase of the shock film is observed up to the 9th second (Figure 12), the film completely covers the surface of the TP. At the 10th second, an explosion occurs, from the lower end of the TP the film begins to collapse. At the 11th second, the nucleate boiling phase NB is observed along the entire height of the TP, which lasts up to the 15th second, after which the cooling moves into the stage of convection. The experimental results presented in Figure 6 and Figure 12, obtained by two independent methods, show a good correlation.

\subsubsection{Video Surveillance of PAA Solutions}

The film boiling phase is observed up to the 15 th second (Figure 13); it completely and evenly covers the surface of the TP up to the 17th second inclusively. At the 18th second, bubbles appear at the lower end of the TP, a "stocking" of the NB phase is formed, which slowly rises upward, displacing the film boiling phase. The process of "putting on the stocking" ends at the 39th second, and at the 41 st second the convection stage starts.

\subsection{Heat Fluxes and Heat Transfer Coefficients}

\subsubsection{Heat Fluxes and Heat Transfer Coefficients in PAG-35 Solutions}

Using the data of cooling curves (Figure 5), presented in Table 1, by the method of IHC solution [34], the dependence of the value of heat fluxes $\mathrm{q}$ (Ts) and the heat transfer coefficient $\alpha$ (Ts) on the surface temperature Ts and the concentration of PAG-35 in water was calculated. Figure 14 shows the heat fluxes of PAG-35 solutions in the concentration range from zero to $10 \%$ wt. Heat fluxes quickly reach high values when the thermal probe is cooled to $700^{\circ} \mathrm{C}$, then a fan-like divergence is observed, reaching the maximum values of $\mathrm{q}(\mathrm{Ts})^{\max }$, which are determined by the polymer concentration. An increase in the concentration of PAG-35 is accompanied by a shift in $\mathrm{q}(\mathrm{Ts})^{\max }$ towards high temperatures from $400^{\circ} \mathrm{C}$ in water to $575^{\circ} \mathrm{C}$ in a $10 \%$ solution of PAG-35, while the value of $\mathrm{q}(\mathrm{Ts})^{\max }$ decreases from $4.1 \mathrm{MW} / \mathrm{m}^{2}$ to $2,2 \mathrm{MW} / \mathrm{m}^{2}$ (Figure 14, curves 1 and 6). This character of the curves of the function $\mathrm{q}$ (Ts) contributes to the homogeneity of the heat transfer process, homogeneous cooling of parts, minimization of residual stresses and the appearance of cracks [17].

The dependence of the heat transfer coefficient $\alpha$ (Ts) on the concentration of PAG-35 and the surface temperature Ts is shown in Figure 15. Addition of 2\%wt. PAG-35 reduces the values of $\alpha(\mathrm{Ts})^{\max }$ by $2000 \mathrm{~W} / \mathrm{m}^{2} \cdot \mathrm{K}$, while the position of $\alpha(\mathrm{Ts})^{\max }$ remains at about $200^{\circ} \mathrm{C}$ (Figure 15 , curve 2$)$. The decrease of $\alpha(\mathrm{Ts})^{\max }$ value can be explained by the formation of a PAG-35 nanoemulsion as a result of the destruction of a shock polymer film, the thermal conductivity of which is lower than that of water. With an increase in the concentration of PAG-35 to $3 \%$ wt. position $\alpha(\mathrm{Ts})^{\max }$ shifts to $320^{\circ} \mathrm{C}$, while its value decreases by $6700 \mathrm{~W} / \mathrm{m}^{2} \cdot \mathrm{K}$ (Figure 15 , curve 3). Taking into account the results of video surveillance (Figure 10), such a significant decrease of $\alpha$ $(\mathrm{Ts})^{\max }$ value can be explained by the fact that the stage of film boiling prevails in the process of heat transfer with such 
a polymer content. The subsequent increase in the concentration of PAG-35 to 5\%wt., $7 \%$ wt. and $10 \%$ wt. accompanied by a synchronous decrease of $\alpha(\mathrm{Ts})^{\max }$ values and their shift towards high temperatures by $100^{\circ} \mathrm{C}, 160^{\circ} \mathrm{C}$ and $200^{\circ} \mathrm{C}$, respectively (Figure 15, curves 4-6).
Consequently, PAG-35 additives smoothly affect the main parameters of the cooling process q (Ts) and $\alpha$ (Ts), which makes it possible to select the composition of water-polymer quenching media in accordance with the requirements of the hardening technology in production conditions.

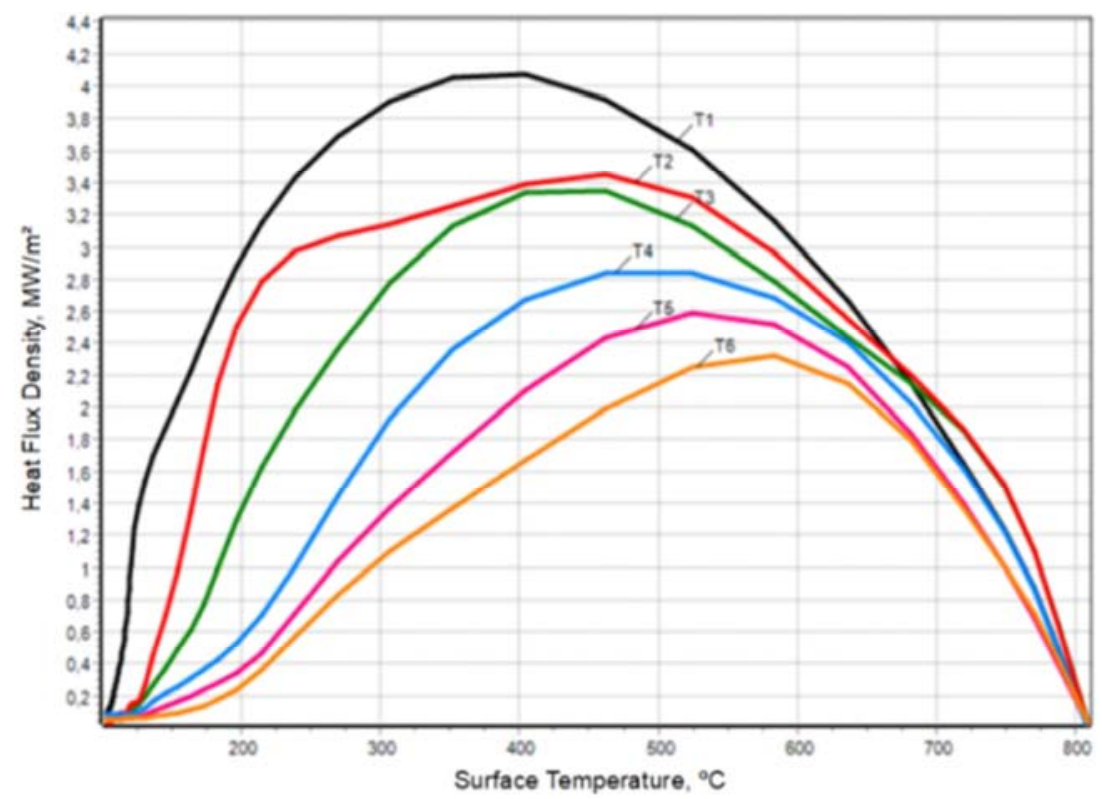

Figure 14. Heat flux density $q(T S)$ in PAG-35 solutions with concentration, \%wt.: 1 - 0.0; 2 - 2.0; 3 - 3.0; 4 - 5.0; 5 - 7.0; 6 - 10.0, T-2 ${ }^{\circ} \mathrm{C}$.

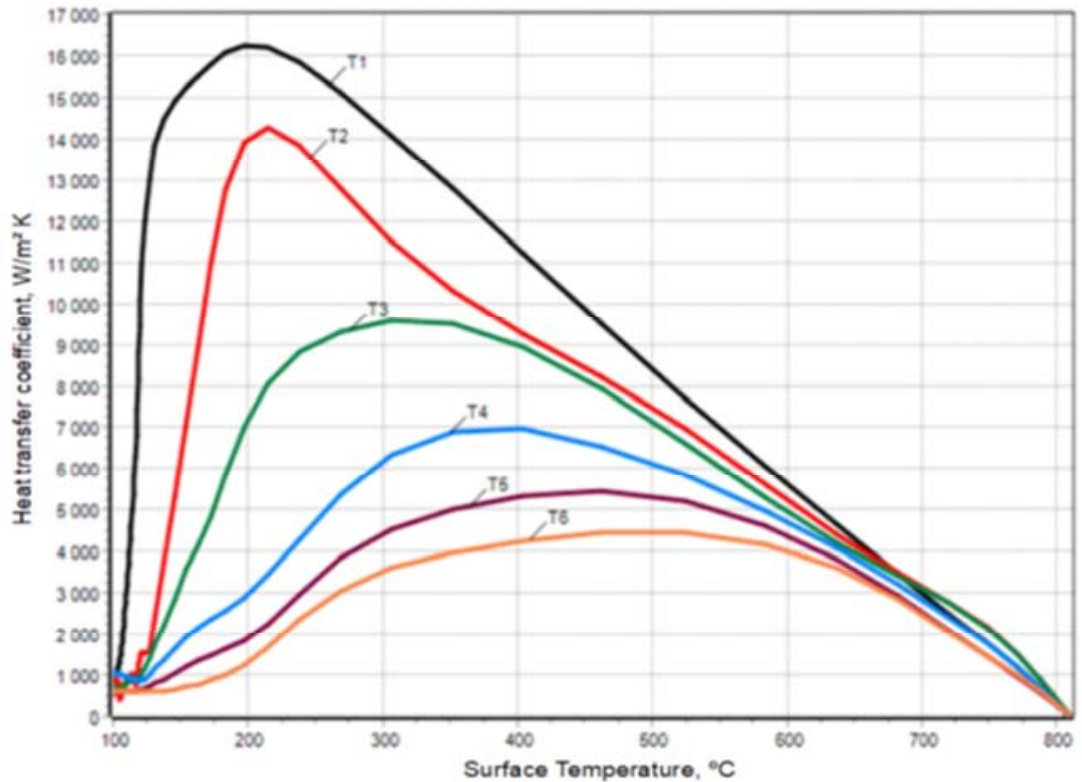

Figure 15. Heat transfer coefficient $\alpha(T S)$ in PAG-35 solutions with concentration, \%wt.: $1-0.0 ; 2-2.0 ; 3-3.0 ; 4-5.0 ; 5-7.0 ; 6-10.0, T-20^{\circ} \mathrm{C}$.

\subsubsection{Heat Fluxes and Heat Transfer Coefficients in Na-CMC Solutions}

Figure 16 shows the results of calculations by the IHC method [34] of heat fluxes $\mathrm{q}(\mathrm{Ts})$ in $\mathrm{Na}-\mathrm{CMC}$ solutions and distilled water. On curve 1, Figure 16, there is a noticeable peak at about $775^{\circ} \mathrm{C}$, which corresponds to boiling of the shock water film [33]. With a decrease of the cooling temperature, a rapid increase of the heat flux is observed, reaching $\mathrm{q}(\mathrm{Ts})^{\max }$ at $440^{\circ} \mathrm{C}$ and a gradual decrease of $\mathrm{q}(\mathrm{Ts})$ values down to $200^{\circ} \mathrm{C}$, after which a sharp drop occurs at a cooling temperature of $150^{\circ} \mathrm{C}$ (Figure 16, curve 1). Addition of $0.25 \%$ wt. Na-CMC into water radically changes the character of the q (Ts) curve (Figure 16, curve 2): rather intense peaks appear at $740^{\circ} \mathrm{C}$ and $700^{\circ} \mathrm{C}$, which should be attributed to the boiling of the shock film [33] and the polymer shock film, respectively, while a small maximum at $600^{\circ} \mathrm{C}$ corresponds to transition boiling [5]. A shift of $\mathrm{q}$ $(\mathrm{Ts})^{\max }$ is observed in the polymer solution up to $300^{\circ} \mathrm{C}$, 
while $\mathrm{q} \mathrm{(Ts})^{\max }$ value decreases from $3.5 \mathrm{MW} / \mathrm{m}^{2}$ in water to $2.75 \mathrm{MW} / \mathrm{m}^{2}$ at $0.25 \%$ wt. Na-CMC solution. Increasing the polymer content to $0.75 \%$ wt., $1.5 \%$ wt. and $2.0 \% \mathrm{wt}$. is accompanied by a proportional decrease of $\mathrm{q}(\mathrm{Ts})^{\max }$ and its shift to $275^{\circ} \mathrm{C}, 240^{\circ} \mathrm{C}$, and $180^{\circ} \mathrm{C}$, respectively (Figure 16 , curves 3,4 and 5). The minimum $\mathrm{q}(\mathrm{Ts})^{\max }$ values are observed in the temperature range of $800^{\circ} \mathrm{C}-530^{\circ} \mathrm{C}$ in $0.75 \%$ wt. solution, $800^{\circ} \mathrm{C}-400^{\circ} \mathrm{C}$ in $1.5 \%$ wt. solution, and $800^{\circ} \mathrm{C}-330^{\circ} \mathrm{C}$ in $2.0 \%$ wt. solution of $\mathrm{Na}-\mathrm{CMC}$ and they correspond to film boiling in a polymer "shell".

The dependence of the heat transfer coefficient $\alpha$ (Ts) of $\mathrm{Na}-\mathrm{CMC}$ solutions in water on the surface temperature Ts is shown in Figure 17. Addition of $0.25 \%$ wt. Na-CMC into water is accompanied by a slight shift of $\alpha(\mathrm{Ts})^{\max }$ from $175^{\circ} \mathrm{C}$ (Figure 17 , curve 1 ) to $185^{\circ} \mathrm{C}$ (Figure 17 , curve 2), while $\alpha(\mathrm{Ts})^{\max }$ value decreases by $20 \%$. Increasing the concentration of the polymer to $0.75 \%$ wt. shifts the position of $\alpha(\mathrm{Ts})^{\max }$ from $185^{\circ} \mathrm{C}$ to $160^{\circ} \mathrm{C}$, i.e. to the area of lower temperatures, which confirms the above assumption about two different heat transfer processes in Na-CMC solutions. With an increase of the polymer content to $1.5 \% \mathrm{wt}$. and $2.0 \%$ wt. the position and $\alpha(\mathrm{Ts})^{\max }$ value practically do not change, however the $\alpha(\mathrm{Ts})^{\max }$ value decreases by $32 \%$ in $0.75 \%$ wt. solution, $45 \%$ in $1.5 \%$ wt. solution and $60 \%$ in $2.0 \%$ wt. Na-CMC solution. Consequently, the addition of $\mathrm{Na}-\mathrm{CMC}$ to water affects both the absolute values of $\mathrm{q}$ $(\mathrm{Ts})^{\max }$ and $\alpha(\mathrm{Ts})^{\max }$ and the position of their maxima, which makes it possible to regulate the properties of the CMC in accordance with the requirements of the technology of heat treatment of metals.

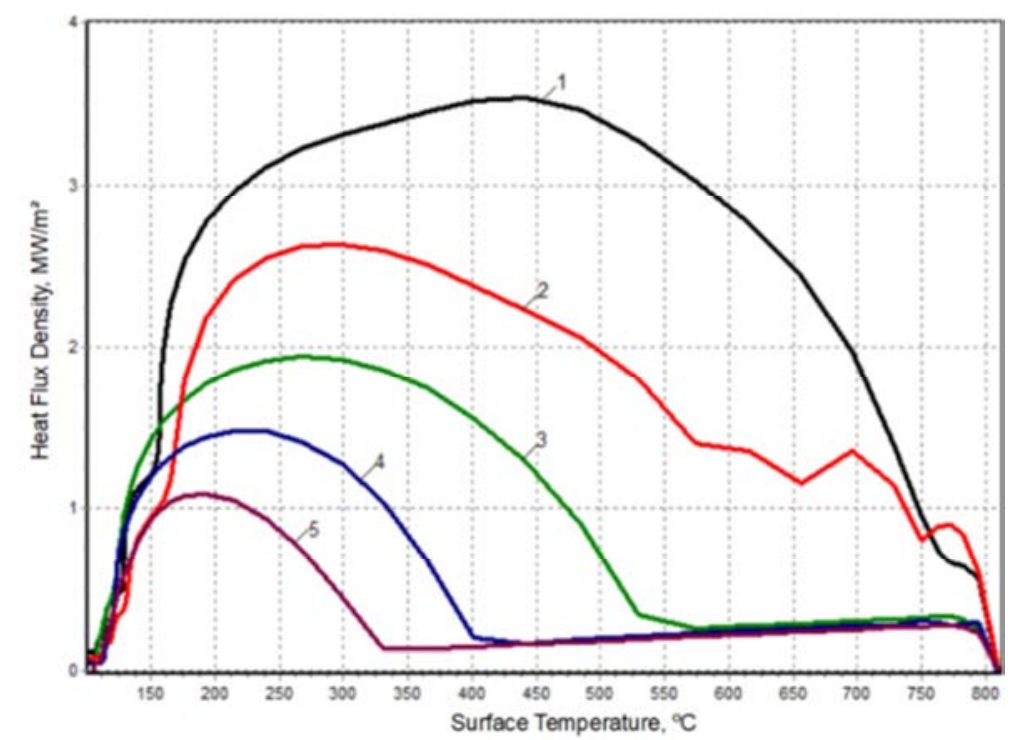

Figure 16. Heat flux density $q(T S)$ in solutions of Na-CMC (Na-CMC) with concentration, \%wt.: $1-0.00 ; 2-0.25 ; 3-0.75 ; 4-1.50 ; 5-2.0$ at $T=20^{\circ} \mathrm{C}$.

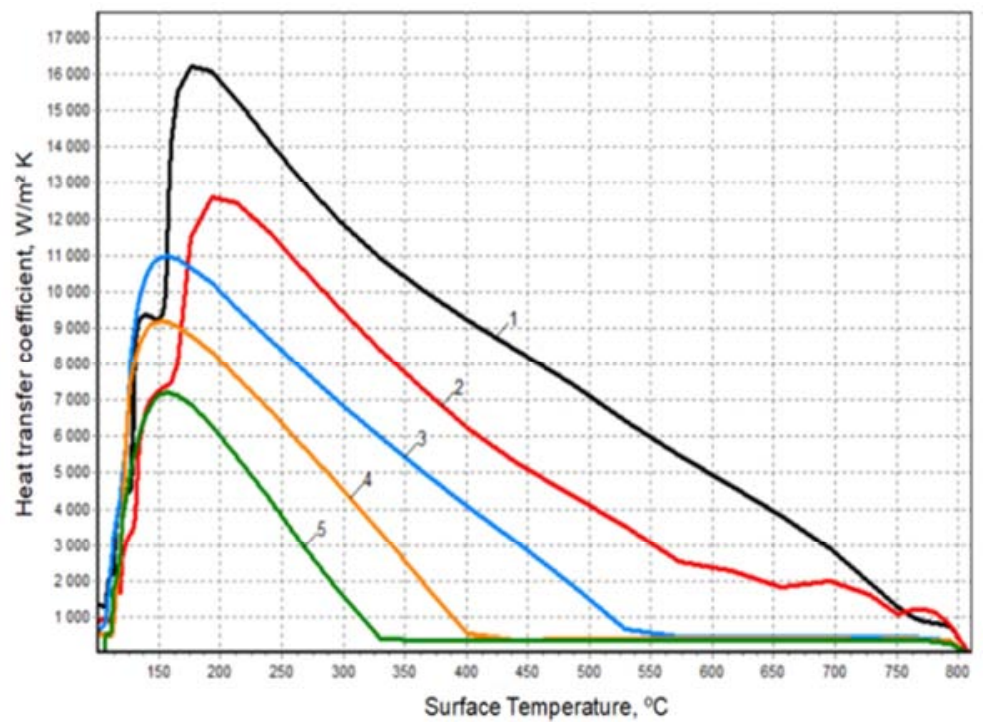

Figure 17. Heat transfer coefficient $\alpha$ (TS) in solutions of Na-CMC (Na-CMC) with concentration, \%wt.: $1-0.00 ; 2-0.25 ; 3-0.75 ; 4-1.50 ; 5-2.0$ at $T=20^{\circ} \mathrm{C}$. 


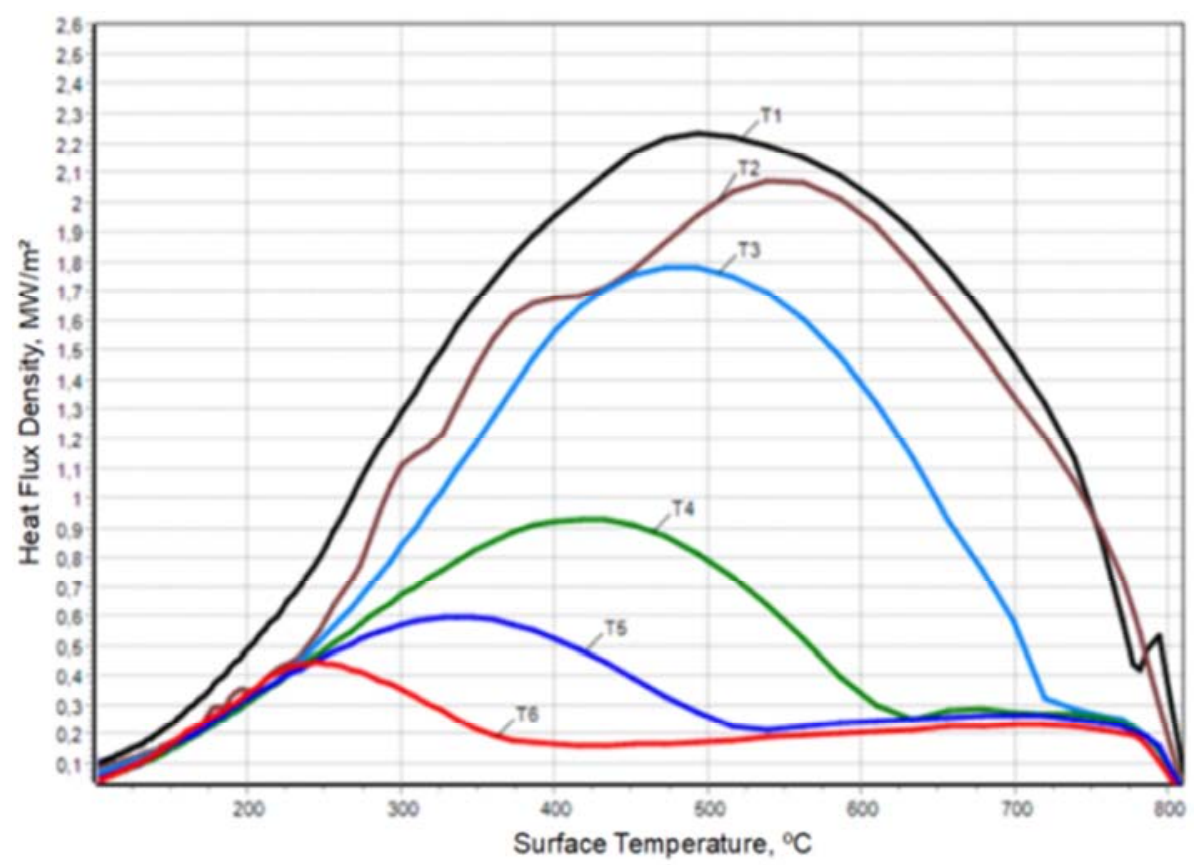

Figure 18. Heat flux density $q(T s)$ in PAA solutions with concentration, \%wt.: $1-0.00 ; 2-0.0075 ; 3-0.015 ; 4-0.03 ; 5-0.05 ; 6-0.10$ at $T=20^{\circ} \mathrm{C}$.

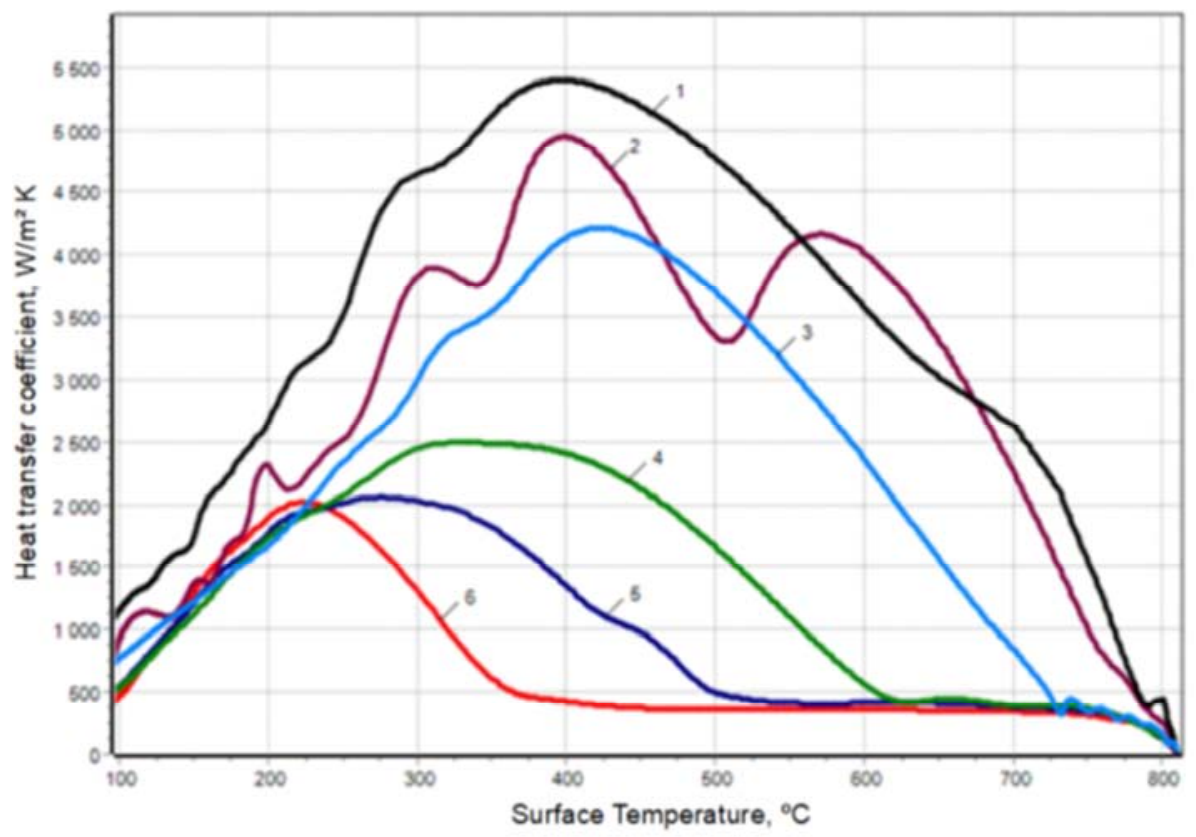

Figure 19. Heat transfer coefficient $\alpha(T S)$ in PAA solutions with concentration, \% wt.: $1-0.00 ; 2-0.0075 ; 3-0.015 ; 4-0.03 ; 5-0.05 ; 6-0.10$ at T=20 ${ }^{\circ} \mathrm{C}$.

\subsubsection{Heat Fluxes and Heat Transfer Coefficients in Polyacrylamide Solutions}

Figure 18 shows heat fluxes q (Ts) in PAA solutions in the concentration range from zero to $0.1 \% \mathrm{wt}$. On curve 1 , Figure 18, there is a small but clear peak at about $785^{\circ} \mathrm{C}$, corresponding to boiling of the shock film of water [33]. Addition of $0.0075 \%$ wt. PAA is accompanied by a noticeable decrease of $\mathrm{q}(\mathrm{Ts})^{\max }$ values, while its position shifts from $500^{\circ} \mathrm{C}$ to $550^{\circ} \mathrm{C}$, and a noticeable inflection is observed around $770^{\circ} \mathrm{C}$ area, which is apparently due to the presence of a powerful shoulder on the curve of the temperature versus cooling rate (Figure 7, c, curve 2). The presence on curve 2,
Figure 18 of noticeable inflections at $400^{\circ} \mathrm{C}$ and $300^{\circ} \mathrm{C}$ can be explained by the presence of a transition boiling regime in this temperature range [5]. Increasing the concentration of PAA to $0.015 \%$ wt. is accompanied by a return of $\mathrm{q}(\mathrm{Ts})^{\max }$ to $500{ }^{\circ} \mathrm{C}$, decrease of its value by $18 \%$ and the appearance of a "shelf" in the range of $720-800^{\circ} \mathrm{C}$ is explained by the formation of a shock polymer film. The subsequent increase in the concentration of PAA to $0.03 \%$ wt., $0.05 \%$ wt. and $0.10 \%$ wt. accompanied by a synchronous decrease of $\mathrm{q}$ (Ts) ${ }^{\max }$ by $60 \%, 72 \%, 79 \%$ and their shift to $430^{\circ} \mathrm{C}, 350^{\circ} \mathrm{C}$ and $220^{\circ} \mathrm{C}$, respectively. The above changes of the $\mathrm{q}$ (Ts) behavior with an increase of the PAA concentration occur 
symbatically with the expansion of the temperature and time range of the film boiling phase (Figure $7(a, b)$ ), (Figure 18, curves 4, 5 and 6).

The dependence of the heat transfer coefficient $\alpha$ (Ts) on the PAA concentration and surface temperature is shown in Figure 19. Addition of $0.0075 \%$ wt. polymer radically changes the $\alpha$ (Ts) curve: it contains three distinct intense maxima at $580^{\circ} \mathrm{C}, 400^{\circ} \mathrm{C}$ and $315^{\circ} \mathrm{C}$, the presence of which can be explained by the metastable character of the $\mathrm{FB}$ phase at ultralow PAA concentrations. Two maxima at $400^{\circ} \mathrm{C}$ and $315^{\circ} \mathrm{C}$ probably correspond to the transition boiling regime in this temperature range [5], followed by a transition to the NB phase. The increase in the concentration of PAA to $0.015 \%$ wt. accompanied by a slight shift of $\alpha(\mathrm{Ts})^{\max }$ to $420^{\circ} \mathrm{C}$, while the $\alpha(\mathrm{Ts})^{\max }$ value decreases by $22 \%$ in relation to $\alpha$ (Ts) $\max$ in water. The subsequent increase of concentration to $0.03 \% \mathrm{wt}$, $\quad 0.05 \% \mathrm{wt}$. and $0.10 \% \mathrm{wt}$. accompanied by a synchronous decrease of $\alpha(\mathrm{Ts})^{\max }$ value by $53 \%, 62 \%$ and $63 \%$ and a shift of their maxima to the range of lower temperatures up to $350^{\circ} \mathrm{C}, 280^{\circ} \mathrm{C}$ and $225^{\circ} \mathrm{C}$, respectively. Analysis of changes in the behavior of $\alpha$ (Ts) shows that there is a symbatic relationship between the decrease of $\alpha(\mathrm{Ts})^{\max }$ and the shift of $\Delta \mathrm{T}^{\max }$ from the PAA concentration. The results presented can be useful in the development of new WPQM for heat treatment of metals.

\section{Discussion}

When analyzing the results obtained, it should be taken into account that of the three selected polymers, only PAG has the property of reversible solubility and belongs to the class of nonionic high molecular weight surfactants [35]. Therefore, these two factors can explain the significant differences in the nature of the concentration dependences of the cooling curves and the cooling rate in PAG-35 solutions (Figure $5(\mathrm{a}, \mathrm{b})$ ) in comparison with $\mathrm{Na}-\mathrm{CMC}$ solutions (Figure $6(a, b))$ and PAA (Figure $7(a, b)$ ).

Comparison of the results obtained by measuring the temperature and cooling rate and video surveillance shows that the process of nonstationary boiling during cooling of TP in PAG solutions is multistage, and the number and sequence of the vapor-liquid phases is determined by the concentration and, consequently, the viscosity of the solutions. In the area of low concentrations (up to $2 \%$ wt.), the cooling process begins at the moment of shock boiling, which ends with the formation of a polymer shock film at the solution-vapor interface. Due to the low concentration of PAG, the thickness, and, consequently, the strength of the film is low, as a result of which it rapidly collapses, rewetting and transition to the NB phase occurs, then cooling moves to the convection phase. With an increase of PAG concentration up to $3 \% \mathrm{wt}$. and $7 \%$ wt. the duration of the boiling stage of the film increases to $4 \mathrm{~s}$ and $5 \mathrm{~s}$, respectively, which can be explained by an increase of the thickness and, consequently, the strength of the polymer film. Comparing the corresponding kinetic curves of the cooling rate (Figure 5, a) for PAG-35 solutions with a concentration of $3 \%$ wt. and $7 \%$ wt. with the results of video surveillance, we can conclude that in the area of average concentrations $(3.0-7.0) \%$ wt. heat transfer occurs mainly in the boiling phase of a film in a polymer shell. This conclusion contradicts the results of a number of studies [4, 36-41], according to which the heat transfer coefficients increase in the following order: $100-250 \mathrm{~W} / \mathrm{m}^{2} \cdot \mathrm{K}(\mathrm{FB})<$ $700-1000 \mathrm{~W} / \mathrm{m}^{2} \cdot \mathrm{K}(\mathrm{CONV})<10^{4}-2 \cdot 10^{4} \mathrm{~W} / \mathrm{m}^{2} \cdot \mathrm{K}(\mathrm{NB})$. Therefore, a version is proposed, according to which, after the formation of a polymer shock film, the bulk of the thermal energy from the heated metal is spent on breaking the H-bonds between the hydrogen of water molecules and the etheric oxygen of PAG macromolecules, i.e. for "dehydration" of polymer chains. Since visually no noticeable turbidity is observed inside the boiling film before the explosion (Figure 8 - Figure 10), therefore, its components are water vapor and individual nanosized PAG macromolecules. According to [37], such systems belong to nanosols (gas + liquid nanoparticles), which obey the corresponding laws of heat and mass transfer. It is possible that under conditions of high temperatures and shear hydrodynamic loads [8], the PAG solution turns into a kind of accumulator of thermal energy. When the inversion temperature in the boundary with the vapor film layer of the solution reached, the PAG loses its solubility and is released from the solution, while the integrity of the phase boundary is violated, the polymer film breaks through and rewetting occurs, i.e. transition to the nucleate boiling phase.

Studies of the cooling and technological properties of waterpolymer quenchants based on Na-CMC and PAA have shown $[29,30]$ that an increase in the concentration of these polymers is accompanied by a noticeable decrease in the cooling capacity of solutions in the upper temperature range; the FB stage becomes more prolonged and stable. Therefore, detailed studies of the cooling capacity of aqueous solutions of Na$\mathrm{CMC}$ and PAA with a known Mm were carried out in a wide range of concentrations. This task is urgent, because WPQM based on these polymers give positive results in the quenching of high-alloy and heat-resistant steels [29, 30, 44]. Despite the large volume of publications on WPQM, there is currently some uncertainty in the cooling mechanism in aqueous solutions of polymers, contradictions in the conclusions when comparing the results of studies of solutions of polymers of different chemical nature [6, 7, 42-44].

The above results allow us to propose a substantiated version of the cooling mechanism of the WPQM. The starting point of our research is the detection of a small peak $\left(1692 \mathrm{~W} / \mathrm{m}^{2} \cdot \mathrm{K}\right)$ of $\alpha(\mathrm{Ts})$ values when the unique Petrofer / Liscic thermal probe is cooled in distilled water, which the author attributed to the stage of shock film "boiling " [33]. When a polymer is added to water, a solution is obtained in which the high-molecular component is, depending on the stereochemistry of macromolecules, a network of entanglements, intermolecular bonds - from hydrogen to ionic, a composition of structural units (Na-CMC nanoparticles) $[21,22,32]$, i.e. a kind of frame. At the moment of shock boiling, it takes on a significant proportion of hydrodynamic and thermal shocks. The substance formed 
at this moment, which is a nanosol (for PAG solutions) or a nanogas suspension (for $\mathrm{Na}-\mathrm{CMC}$ and PAA solutions) [37], under the action of a shock wave is directed from the hot metal surface to the interface between the phases of a vaporpolymer solution, thus forming polymer impact film.

\section{Conclusion}

Taking into account the presented research results and presented in $[9,45]$, it can be assumed that one of the stages of the impact mechanism of the formation of a polymer film is the adsorption increase in the polymer concentration on the surface of bubbles formed during impact boiling. During the next stage the polymer shell of the bubbles is spent on the formation of an interfacial polymer film. Depending on the chemical nature, physicomechanical properties, and polymer content, the boiling phase of such a bilayer film can be shortor long-term, because its duration increases with an increase of the strength properties of polymers: $\mathrm{PAA}>\mathrm{Na}-\mathrm{CMC}>\mathrm{PAG}-$ 35. An analysis of the concentration and kinetic curves of TP cooling shows that the threshold concentrations at which an impact polymer film is formed increase in the following order: $0.015 \%$ (PAA) $<0.4 \%(\mathrm{Na}-\mathrm{CMC})<2.0 \%$ (PAG) with practically the same viscosity of polymer solutions.

The proposed mechanism for the formation of an interfacial heat-insulating film (HIF) allows us to resolve the contradiction arising in the case of accepting the option of forming a HIF on the surface of a hot metal [7, 38-41]. In this case, the initial heat flux $\mathrm{q}_{\mathrm{ntp}}$ immediately decreases, it becomes less than $\mathrm{q}_{\mathrm{cr}}{ }^{1}$, and then the immediate destruction of the FB phase follows. Since, according to the above results, the FB phase is sufficiently stable in solutions of Na-CMC and PAA, and in PAG solutions with a concentration of less than $2 \%$ wt. its rapid destruction occurs due to the manifestation of the effect of reversible solubility, therefore, HIF, i.e. polymer film, formed at the interface between the phases, a polymer solution-vapor film by an impact mechanism.

\section{Acknowledgements}

The authors express their sincere gratitude to Larisa Karsim, Aleksandra Moskalenko, and Boris Shchegolev for sharing their knowledge and experience, for their efforts and professional support in conducting experimental studies, processing the results, and article preparation.

\section{References}

[1] Kobasko N. I., Shvets Yu. I., Fialko N. M., Meranova N. O., Nikolaev E. D. Cooling capacity of an aqueous solution of PK-2 polymer at different temperatures. Metallurgy and heat treatment of metals. 1985. No. 9. pp. 2-5.

[2] Kobasko N. I., Timchenko N. G. A cinematic study of the cooling process of samples in aqueous polymer solutions. MiTOM, 1986. No. 10, pp. 25-29.

[3] Kobasko N. I. Increasing the service life of machine parts and tools by intensifying their cooling during quenching. MiTOM, 1986. No. 10, pp. 47-52.

[4] Tensi H. M., Stitzelberger J. P. Influence of rewetting on hardening processes // Industrial heat engineering. 1989.-11, No. 4, pp. 57-66.

[5] Kobasko N. I. Technological aspects of cooling during quenching (review). MITOM, 1991. No. 4. pp. 2-8.

[6] Kobasko N. I., Krivoshey F. A. On the mechanism of temperature and heat flux fluctuations during cooling of metal samples in aqueous solutions of polymers. Reports of the Academy of Sciences of Ukraine. 1994. No. 11. pp. 90-94.

[7] Kobasko N. I., Moskalenko A. A. Intensification of hardening methods by using aqueous polymer solutions. Industrial heating technology. 1996. No. 6. pp. 55-60.

[8] Moskalenko A. A., Kobasko N. I., Tolmacheva O. V., Totten G. T., Webster G. M. (1996) Quenchants Characterization by Acoustical Noise Analysis of Cooling Properties of Aqueous Poly (Alkylene Glycol) Polymer Quenchants. Proc. of the 2nd Int. Conf. on Quenching and Control of the Distortion. (USA). pp. 117-122.

[9] Waldeck S., Castens M., Riefler N., Frerichs F., Lubben Th. and Fritsching U. HTM Journal of Heat Treatment and Materials, 2019, 74, 4, p. 238-256.

[10] G. V. Kovalenko, N. I. Kobasko Simulation of unsteady boiling during quenching cooling in water. Industrial heating technology. 1986, T. 8, No. 6, pp. 29-35.

[11] Mikita Y., Nakabayashi I., Ohga N., and Ohsaka K. Hippon Kikai Gakkai Ronbunshu (A-hen). Vol 53 (No. 496).1987. pp. 2211-2215.

[12] Nikolaev A. F., Okhrimenko G. I. Water-soluble polymers. -L.: Chemistry, 1979.-144p.

[13] Lipatov Yu. S., Sergeeva L. M. Adsorption of polymers. Naukova Dumka. Kiev. -1972.-195p.

[14] Privalko V. P., Novikov V. V., Yanovskiy Yu. G. Fundamentals of Thermophysics and Rheophysics of Polymeric Materials. Kiev: Naukova Dumka, -1991.-232p.

[15] Totten G. E. Polymer Quenchants for Induction Heat Treating Applications: The Basics. In 9th International Induction Heat Treating Seminar, FL, May 2000. https://www.researchgate.net/publication/228480536.

[16] Kobacko N. I., Real and Effective Heat Transfer Coefficients (NTCs) Used for Computer Simulayion of Transient Nucleate Boiling Processes During Quenching Materials Performance and Characterization, 2012, Vol. 1, No. 1, pp. 1-20.

[17] Zordao L. P., Oliveria V. A., Totten G. E., Canale L. C. F. Quenching Power of Aqueous Salt Solution., International Journal of Heat and Mass Transfer, 140 (2019), p. 807-818.

[18] https://www.xumuk.ru/spravochnik/329.html.

[19] Madorsky S. L. Thermal Degradation of Organic Polymers. New York-London-Sydney. 1964.-351p.

[20] Lohvynenko P. N., Moskalenko A. A., Kobasko N. I., Karsim L. O., Riabov S. V. Experimental Investigation of Effect of Polyisobutilene Additives to Mineral Oil on Cooling Characteristics. Materials Performance and Characterization. 2016, 5 (1), pp. 1-13. 
[21] Gul V. E., Kuleznev V. N. Structure and mechanical properties of polymers. M.: "High school", 1972.-320p.

[22] Tager A. A. Physicochemistry of polymers. M., Goskhimizdat. 1963.-528p

[23] Tkachuk T. I., Rudakova N. Ya., Sheremet B. K., Novoded R. D. Possible Ways to Reduce the Film Boiling Period when Quenching in Petroleum Oils. Metallurgy and Heat Treatment of Metals. 1986, No. 10. pp. 42-44.

[24] Faynerman A. E., Lipatov Yu. S., Kulik V. M., Vologina L. N., Simple Metnod for Determination of the Surface Tension and Contact Angler of Wetting of Liquids. Colloid journal. 1970. T XXXII. No. 4. pp. 620-623.

[25] Ramesh, G., Narayan Prabhu, K. (2016). Effect of Polymer Concentration on Wetting and Cooling Performance During Immersion Quenching. Metall and Materi Trans B 47, pp. 859-881.

[26] Mathews N. D., Rao K. M. P., Nayak V., Prabhu K. N. Comparison of Cooling Behaviors of Carbon Steels in Polymer, Oil and Carbonated Quench. Media. Trans actions of the Indian Institute of Metals. January 2019. P. 1-6.

[27] Onan M., Unan H. I., Onan C., Atapek I. Y. (2014). Understanding of Polymer Quenchants (Polyalkyleneglycol) Characteristic During Quenching Process of Tool Steels. International Journal Microstructure and Materials Properties, V. 9, No. 1, pp. 71-78.

[28] Kobasco N. I. Steel Quenching in Liquid Media Under Pressure. Naukova Dumka, Kyiv, 1980-.216p.

[29] Batte A. D., Marfi M. K., Fishe K. et al. Industrial heat treatment of steam turbine rotors made of chromiummolybdenum-vanadium steels. Ferrous metallurgy. 1979. No. 18. Pp. 14-19.

[30] Okhrimenko T. V., Kuznetsov I. B., Lanin A. A. et al. Experience of hardening heat-resistant steels in a polymer environment based on Na-CMC. MiTOM, No. 4, 1991, p. 2124.

[31] Babu K., Prasanna Kumar T. S. Effect of CNT Concentration and Agitation on Surface Heat Flux During Quenching in CNT Nanofluids. International Journal of Heat Transfer, 2011, V. 54. pp. 106-117.

[32] Shachneva Yu. Yu., Magomedova Z. A., Malagieva Kh. Z. Study of the physicochemical properties of carboxymethylcellulose (CMC) particles in aqueous solutions. Technique and technology of food production. 2014, No. 1, pp. 152-156.

[33] Liscic B "Measurement and Recording of Quenching Intensity in Workshop Conditions Based on Temperature Gradients," Materials Performance and Characterization, Vol. 5, No. 1. 2016. pp. 202-219.
[34] Zotov E. N., Moskalenko A. A., Razumtseva O. V., Protsenko L. N., Dobrivecher V. V. Features of the Application of the IQLab Program for Solving the Inverse Problem of Heat Conduction for Chromium-Nickel Cylindrical Thermal Probes. Industrial Heat Engineering. 2018. Vol. 40, No. 3, pp. 91-96.

[35] H. Polat, S. Chander Adsorption of PEO: PPO triblock copolymers and wetting of coal / Colloids and Surfaces A: Physicochem. Eng. Aspects. -1999. V. 146. N 1-3.-p. 199-212.

[36] Hernandez-Morales B., Vergara-Hernandez H. J., Solorio-Diaz G. and Totten G. E., Experimental and Computational Study of Heat Transfer During Quenching of Metallic Probes. Evaporation, Condensation and Heat transfer. September 12th 2011, DOI: $10.5772 / 24469$.

[37] Rudyak V. Ya., Belkin A. A. Modeling the transfer coefficients of nanofluids. Nanosystems: physics, chemistry, mathematics, 2010, Vol. 1, No. 1, pp. 156-177.

[38] Kobasko N. Research on New Ways of Decreasing Distortion of Steel Parts During Hardening in Liquid Media. Asian Journal of Science and Technology Vol. 08, Issue, 08, pp. 5299-5304, August, 2017.

[39] Kobasko N., Moskalenko A., Dobryvechir V. Research on Use of Low Concentration Inverse Solubility Polymers in Water for Hardening Machine Components and Tools. "EUREKA: Physics and Engineering", 2018, No. 2, pp. 63-71.

[40] Kobasko N. I., Intensive steel quenching processes taking place in liquid media that are considered from the point of view of modern physics. International Journal of Physics and Applications. V. 1, Issue 2, 2019, pp. 16-26.

[41] Kobasko N. I., Uniform and Intense Cooling During Hardening Steel in Low Concentration of Water Polymer Solutions. American Journal of Modern Physics, V. 8, No. 6, 2019, pp. 76-85.

[42] Tsukrov S. L., Komov V. I., Mirzabekova N. S. Water-polymer quenching medium Laprol-ZS. MITOM, No. 4, 1993, pp. 5-7.

[43] Belanov A. A., Kutyev A. P., Mirzabekova N. S. and other Research of polymer hardening environment ZAK-PG. MiTOM, No. 2, 1999, pp. 7-11.

[44] Goryushin V. V., Shevchenko S. Yu. On the use of polymer quenching media in industry. MITOM, No. 6, 2010, p. 26-30.

[45] Logvynenko P. N., Moskalenko A. A., Kobasko N. I., Razumtseva O. V., Karsim L. O. and Riabov S. V. Oligomeric Mechanism of Film Boilimg Elimination (EFB Effect) During Metal Quenching in Solutions of Polyisobutylene in Mineral Oil. International Journal of Current Research Vol. 11, Issue, 09, pp. 7333-7339, September, 2019. 